\title{
Laboratory Experiments on the Effects of Blade Strike from Hydrokinetic Energy Technologies on Larval and Juvenile Freshwater Fishes
}

\section{March 2012}

\section{Prepared by}

Peter E. Schweizer, Glenn F. Cada, and Mark S. Bevelhimer

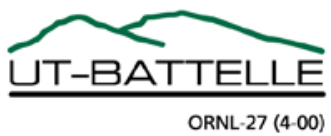




\title{
DOCUMENT AVAILABILITY
}

Reports produced after January 1, 1996, are generally available free via the U.S. Department of Energy (DOE) Information Bridge.

Web site http://www.osti.gov/bridge

Reports produced before January 1, 1996, may be purchased by members of the public from the following source.

\author{
National Technical Information Service \\ 5285 Port Royal Road \\ Springfield, VA 22161 \\ Telephone 703-605-6000 (1-800-553-6847) \\ TDD 703-487-4639 \\ Fax 703-605-6900 \\ E-mail info@ntis.gov \\ Web site http://www.ntis.gov/support/ordernowabout.htm
}

Reports are available to DOE employees, DOE contractors, Energy Technology Data Exchange (ETDE) representatives, and International Nuclear Information System (INIS) representatives from the following source.

Office of Scientific and Technical Information

P.O. Box 62

Oak Ridge, TN 37831

Telephone 865-576-8401

Fax 865-576-5728

E-mail reports@osti.gov

Web site http://www.osti.gov/contact.html

This report was prepared as an account of work sponsored by an agency of the United States Government. Neither the United States Government nor any agency thereof, nor any of their employees, makes any warranty, express or implied, or assumes any legal liability or responsibility for the accuracy, completeness, or usefulness of any information, apparatus, product, or process disclosed, or represents that its use would not infringe privately owned rights. Reference herein to any specific commercial product, process, or service by trade name, trademark, manufacturer, or otherwise, does not necessarily constitute or imply its endorsement, recommendation, or favoring by the United States Government or any agency thereof. The views and opinions of authors expressed herein do not necessarily state or reflect those of the United States Government or any agency thereof. 
Environmental Sciences Division

FY 2011 Annual Progress Report

\title{
LABORATORY EXPERIMENTS \\ ON THE EFFECTS OF BLADE STRIKE \\ FROM HYDROKINETIC ENERGY TECHNOLOGIES ON LARVAL AND JUVENILE FRESHWATER FISHES
}

\author{
P. E. Schweizer \\ G. F. Cada \\ M. S. Bevelhimer
}

Date Published: March 2012

\author{
Prepared for the \\ Water Power Program \\ Office of Energy Efficiency and Renewable Energy \\ U.S. Department of Energy \\ Washington, D.C
}

Prepared by

OAK RIDGE NATIONAL LABORATORY

Oak Ridge, Tennessee 37831-6283

managed by

UT-BATTELLE, LLC

for the

U.S. DEPARTMENT OF ENERGY

under contract DE-AC05-00OR22725 



\section{CONTENTS}

Page

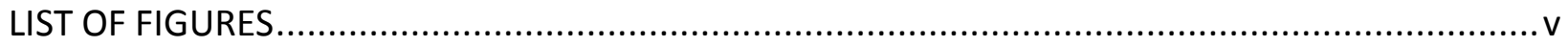

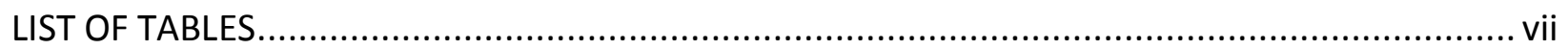

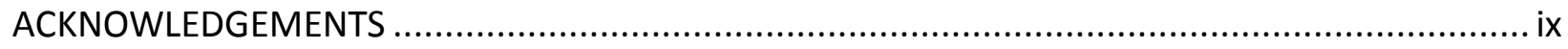

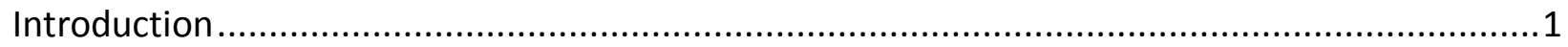

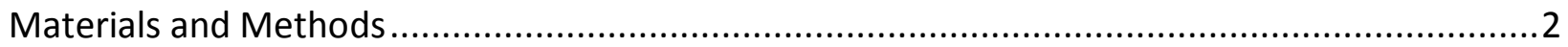

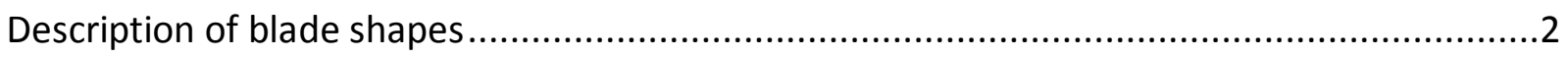

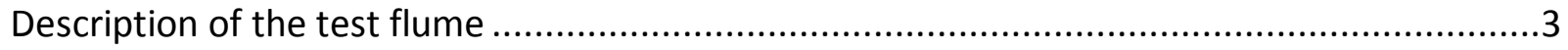

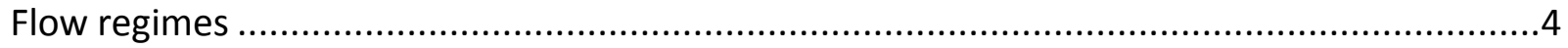

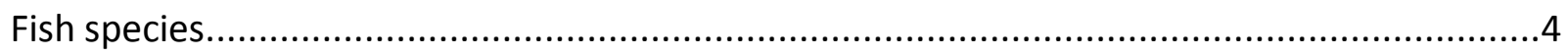

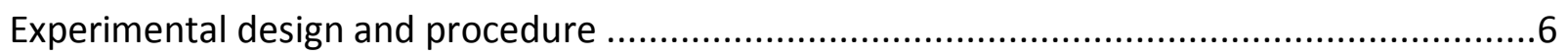

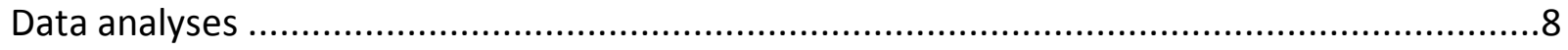

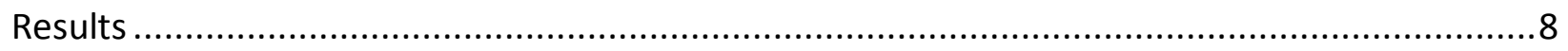

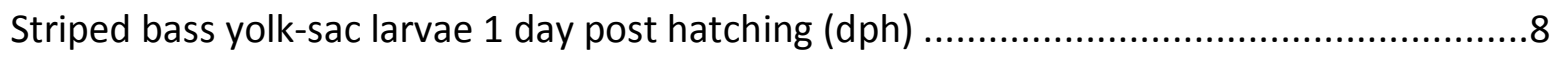

Striped bass age 11 to 14 days post hatching...................................................10

Walleye/sauger age 30 days post hatching .....................................................18

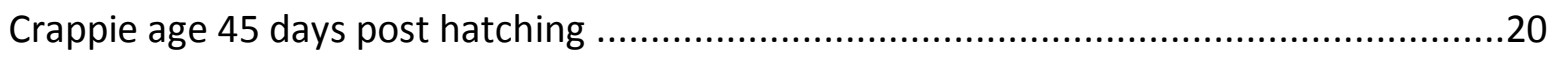

Fathead minnow age cohort 21 to 30 days post hatching .........................................22

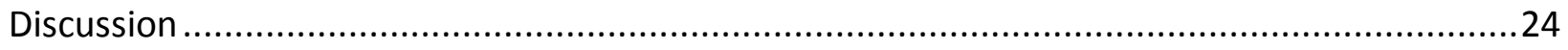

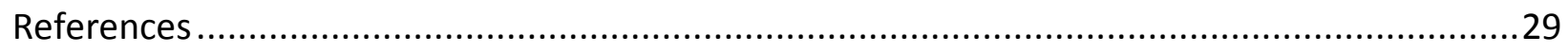





\section{LIST OF FIGURES}

Page

Figure 1. Schematic diagram of the flume used for HK blade strike experiment. .....................3

Figure 2. Investigator measuring flow velocities near location of larval fish insertion point........4

Figure 3. Circular flume setup showing outboard motor with propeller to create different flow

velocities (background) and Acoustic Doppler Velocimeter (ADV) flow meter.........................5

Figure 4. Conceptual flowchart used to derive number of treatments and calculation of minimum sample size needed. Note: not all age groups were available for experimental treatment.

Figure 5. Striped bass survivorship among earliest life-stage (1 day post-hatching) exposed to passage by a 4.0-centimeter-diameter cylinder profile in a $0.5 \mathrm{~m} / \mathrm{sec}$ velocity current. Conditional mortality at time 24 hours post passage $\left(T_{24}\right)$ was 15.0 percent, with 17.2 percent larval survival in the passage-treatment and 68.0 percent in the passage-control, respectively. .9

Figure 6. Percent survival for striped bass aged 11-14 days post-hatching after exposure to a round (cylindrical) blade profile in a $0.85 \mathrm{~m} / \mathrm{sec}$ current.

Figure 7. Percent survival for striped bass aged 11-14 days post-hatching after exposure to a hydrofoil-shaped blade profile in a $0.85 \mathrm{~m} / \mathrm{sec}$ current.

Figure 8. Percent survival for striped bass aged 11-14 days post-hatching after exposure to a pointed blade profile in a $0.85 \mathrm{~m} / \mathrm{sec}$ current.

Figure 9. Percent survival for striped bass aged 11-14 days post-hatching after exposure to a round (cylindrical) blade profile in a $1.15 \mathrm{~m} / \mathrm{sec}$ current.

Figure 10. Percent survival for striped bass aged 11-14 days post-hatching after exposure to a hydrofoil-derived blade profile in a $1.15 \mathrm{~m} / \mathrm{sec}$ current.

Figure 11. Percent survival for striped bass at age 11-14 days post-hatching after exposure to a pointed blade profile in a $1.15 \mathrm{~m} / \mathrm{sec}$ current.

Figure 12. Survival of walleye/sauger (age 30 days post hatching) upon blade encounter in currents of $0.5 \mathrm{~m} / \mathrm{sec}$ velocity. The $\mathrm{Y}$-axis indicates survival rate expressed in percent, the $X$-axis indicated time in hours past exposure to the blade profile in a $0.5 \mathrm{~m} / \mathrm{sec}$ current. 


\section{LIST OF FIGURES (cont'd)}

\section{Page}

Figure 13. Percent survival of crappies (age 45 days post hatching) following blade encounter in currents of $0.85 \mathrm{~m} / \mathrm{sec}$ velocity. Passage-treatment round indicates exposure to a round blade profile (treatment mortality $=0 \%$ ); Passage-treatment hydrofoil indicates exposure to the hydrofoil rotor shape (treatment mortality $=2.1 \%$ ). Note: data for Holding-control and Passage-control were not collected due to small numbers of available fish

Figure 14. Percent survival for fathead minnow (age cohort 21 - 30 days post hatching) upon exposure to different blade cross section profiles in currents with $1.0 \mathrm{~m} / \mathrm{sec}$ velocity. 


\section{LIST OF TABLES}

Page

Table 1. Fish species with total length and age groups tested for mean percent survivorship following encounter at different flow velocities with contrasting rotor blade cross sections in circulating currents.

Table 2. Mortality rates for striped bass early-life stages ( $1 \mathrm{dph}$ ) after encounter of a cylindrical rotor cross section in $0.5 \mathrm{~m} / \mathrm{sec}$ current velocity. 10

Table 3. Mortality rates for striped bass early-life stages (11-14 dph) in $0.85 \mathrm{~m} / \mathrm{sec}$ current and encounter with different shapes for rotor blade cross sections.

Table 4. Mortality rates for striped bass post-yolk-sac larvae (11- $14 \mathrm{dph})$ in $1.15 \mathrm{~m} / \mathrm{sec}$ current and encounter with different shapes for rotor blade cross sections.

Table 5. Survival rates for walleye/sauger age 30 days post hatching, in $0.5 \mathrm{~m} / \mathrm{sec}$ current velocity and exposure to round (cylindrical) blade cross section.

Table 6. Survival rates for crappie aged 45 days post hatching, in $1.15 \mathrm{~m} / \mathrm{sec}$ current velocity and exposure to different rotor blade currents in circulating currents.

Table 7. Mortality rates for fathead minnows ( $21-30 \mathrm{dph})$ in $1.0 \mathrm{~m} / \mathrm{sec}$ current and encounter with different shapes for rotor blade cross sections.

Table 8. Technical specifications of example hydrokinetic devices and the projected velocities at the leading edges for various positions along the rotor blade. Projected blade velocities are estimated for conditions with optimized river flow and device performance. 



\section{ACKNOWLEDGEMENTS}

Fish were obtained from the Tennessee Wildlife Resource Agency's Eagle Bend Fish Hatchery in Clinton, Tennessee. We thank Mike Smith and his staff for their generous assistance, and for sharing their expertise and advice in maintaining early life-stages fishes.

Fish were housed and cared for under the guidelines of the Oak Ridge National Laboratory Animal Care and Use Committee (Protocol ACUC No. 0409).

We thank Constantin Scherelis, Pablo Rosado, and Max Cange for their assistance in carrying out the experiments, Vincent Neary for advice on flume hydrology, and Sreekanth Bangaru and Budi Gunawan for efforts related to ADV measures. Jocelyn Brown-Saracino and Anna Coffey provided valuable comments on an earlier manuscript.

This research was supported by the United States Department of Energy's (DOE) Office of Energy Efficiency and Renewable Energy, Water Power Program. Oak Ridge National Laboratory is managed by UT-Battelle, LLC, for the DOE under contract DE-AC05- 00OR22725. 



\section{Introduction}

There is considerable interest in the development of marine and hydrokinetic energy projects in rivers, estuaries, and coastal ocean waters of the United States. Hydrokinetic (HK) technologies convert the energy of moving water in river or tidal currents into electricity, without the impacts of dams and impoundments associated with conventional hydropower or the extraction and combustion of fossil fuels. The Federal Energy Regulatory Commission (FERC) maintains a database that displays the geographical distribution of proposed HK projects in inland and tidal waters (FERC 2012). As of March 2012, 77 preliminary permits had been issued to private developers to study HK projects in inland waters, the development of which would total over 8,000 MW. Most of these projects are proposed for the lower Mississippi River. In addition, the issuance of another 27 preliminary permits for HK projects in inland waters, and 3 preliminary permits for HK tidal projects (totaling over 3,100 MW) were under consideration by FERC.

Although numerous HK designs are under development (see DOE 2009 for a description of the technologies and their potential environmental effects), the most commonly proposed currentbased projects entail arrays of rotating devices, much like submerged wind turbines, that are positioned in the high-velocity (high energy) river channels. The many diverse HK designs imply a diversity of environmental impacts, but a potential impact common to most is the risk for blade strike to aquatic organisms.

In conventional hydropower generation, research on fish passage through reaction turbines at low-head dams suggested that strike and mortality for small fish could be low. As a consequence of the large surface area to mass ratio of small fish, the drag forces in the boundary layer flow at the surface of a rotor blade may pull small fish around the leading edge of a rotor blade without making physical contact (Turnpenny 1998, Turnpenny et al. 2000). Although there is concern that small, fragile fish early life stages may be unable to avoid being struck by the blades of hydrokinetic turbines, we found no empirical data in the published literature that document survival of earliest life-stage fish in passage by rotor blades. In addition to blade strike, research on passage of fish through conventional hydropower turbines suggested that fish mortalities from passage through the rotor swept area could also occur due to shear stresses and pressure chances in the water column (Čada et al. 1997, Turnpenny 1998). However, for most of the proposed HK turbine designs the rotors are projected to operate a lower RPM (revolutions per minute) than observed from conventional reaction turbines; the associated shear stress and pressure changes are expected to be lower and pose a smaller threat to fish survival (DOE 2009). Only a limited number of studies have been conducted to examine the risk of blade strike from hydrokinetic technologies to fish (Turnpenny et al. 1992, Normandeau et al. 2009, Seitz et al. 2011, EPRI 2011); the survival of drifting or 
weakly swimming fish (especially early life stages) that encounter rotor blades from hydrokinetic (HK) devices is currently unknown.

Our study addressed this knowledge gap by testing how fish larvae and juveniles encountered different blade profiles of hydrokinetic devices and how such encounters influenced survivorship.

We carried out a laboratory study designed to improve our understanding of how fish larvae and juvenile fish may be affected by encounters with rotor blades from HK turbines in the water column of river and ocean currents. (For convenience, these early life stages will be referred to as young of the year, YOY). The experiments developed information needed to quantify the risk (both probability and consequences) of rotor-blade strike to YOY fish. In particular, this study attempted to determine whether YOY drifting in a high-velocity flow directly in the path of the blade leading edge will make contact with the rotor blade or will bypass the blade while entrained in the boundary layer of water flowing over the blade surface. The study quantified both immediate and delayed mortalities (observed immediately, 3 hours, and 24 hours after encountering the blade) among freshwater YOY fish resulting from contact with the blade or turbulent flows in the wake of the blade.

\section{Materials and Methods}

This laboratory study investigated the survival of YOY fish entrained in water flowing past different shapes of rotor blades or cylinders that are representative of moving parts on HK devices. We evaluated how encounters with contrasting rotor blade profiles at different flow velocities affected survival of YOY fish during their first few weeks post hatching. Larvae and juveniles were obtained from a local fish hatchery and held in aquaria for 24 to 48 hours for acclimatization and recovery from transport. Following acclimatization and recovery, fish were entrained in water currents in a circular flume at velocities ranging from $0.5 \mathrm{~m} / \mathrm{s}$ to a maximum of $1.15 \mathrm{~m} / \mathrm{s}$ and were exposed to three different blade profiles. These flow rates are representative of cut-in speed and the lower performance envelope of proposed $\mathrm{HK}$ technologies (DOE 2009) and in large rivers, fish larvae of pelagic broadcast spawners, such as freshwater drum or striped bass, experience exposure to similar and higher flow rates.

\section{Description of blade shapes}

Three different rotor blade profiles with contrasting shapes in cross section (cylinder, hydrofoil shaped, or two-edged/pointed) were constructed from galvanized sheet metal and PVC pipes (see Figure 1 insert). Each of the profiles measured $60 \mathrm{~cm}$ in length (sufficient to extend from the bottom of the flume to above the water surface), and was $4 \mathrm{~cm}$ wide at its widest point. Although the blade profiles were not built to a specific scale they were comparable in size and resembled generalized rotor blade profiles described in the literature (DOE 2009). 


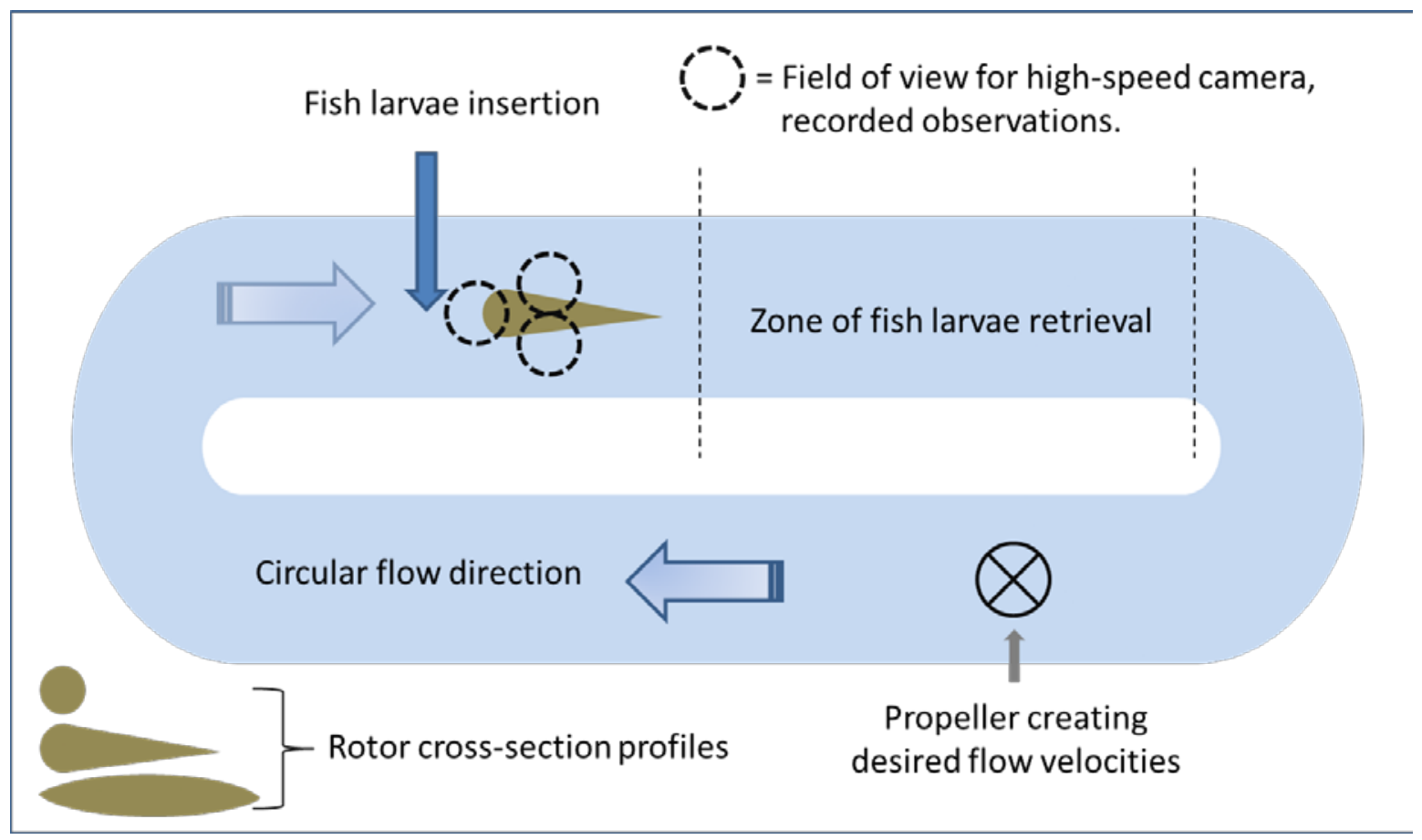

Figure 1. Schematic diagram of the flume used for HK blade strike experiment.

\section{Description of the test flume}

A circulating current flume (two straight sides with dimensions $500 \mathrm{~cm}$ long $X 32 \mathrm{~cm}$ wide X $30 \mathrm{~cm}$ deep) was filled to $25 \mathrm{~cm}$ depth with de-chlorinated tap water at room temperature. The circulating current was created by a battery-powered trolling motor located at the opposite end from the treatment side (Figure 1). Along the treatment side of the flume, acrylic panels were used to decrease the cross section area of the flume (to increase maximum flow velocity attainable given the dimensions of the flume). Cross-sectional dimensions of the area reduced by the acrylic panels were $21 \mathrm{~cm}$ deep by $28 \mathrm{~cm}$ wide. Individual rotor blade profiles (one at the time) were positioned at mid-channel distance in the flume within the reduced crosssectional area. Blade profiles were held in position by metal clamps attached to weighted ring stands placed outside the flume. Flow velocities of the circulating current were measured using an electromagnetic sensor (Streameter 2000, Oppo IT) and adjusted to the desired velocity using the throttle of the electric trolling motor (Figure 2). A transparent vinyl tube with an inner diameter of 18 millimeter was used for insertion of YOY into the circulating current. The discharge end of the tube was positioned at 0.6 maximum depth from the floor of the flume and at a horizontal location upstream equal to 2 diameters (i.e., $8 \mathrm{~cm}$ ) of the blade profile to be tested. 


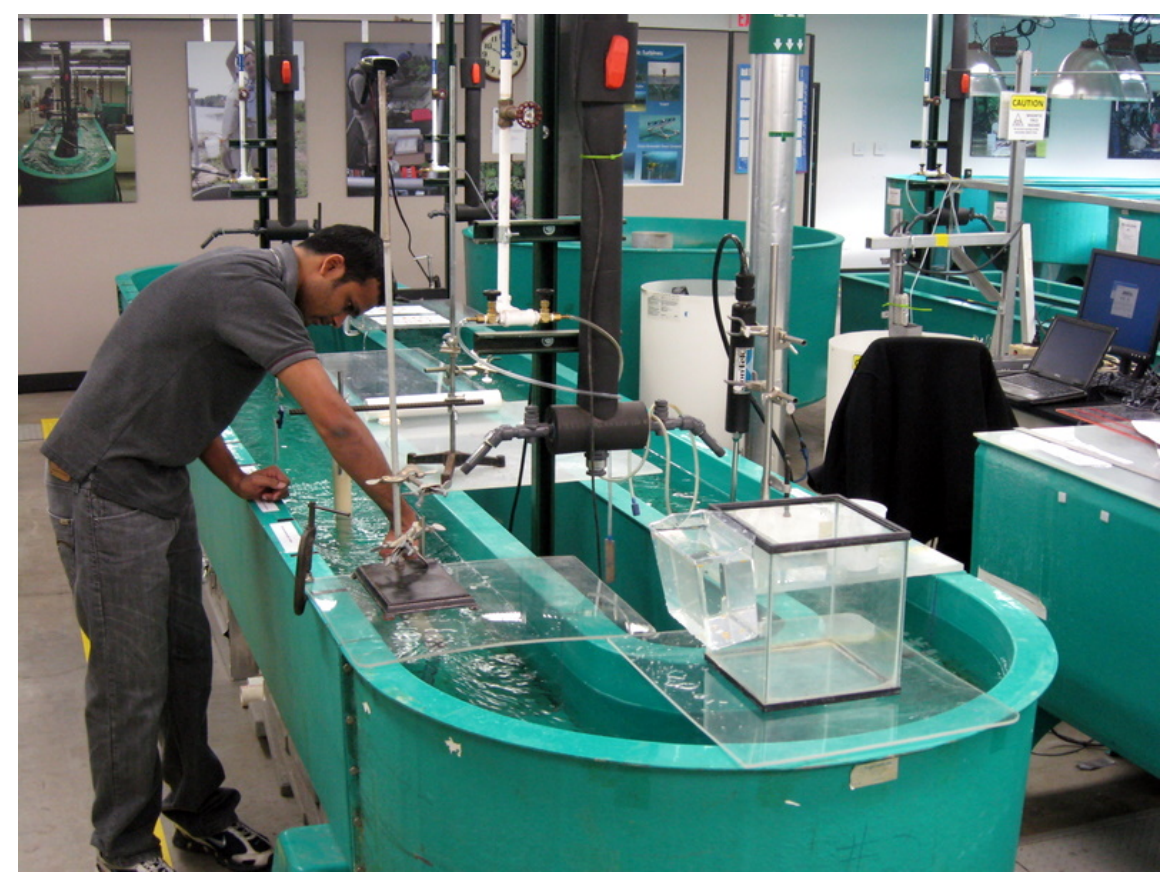

Figure 2. Investigator measuring flow velocities near location of larval fish insertion point.

\section{Flow regimes}

To expose early-life stage fishes in experimental procedure to different flow regimes, flow velocities of the circulating current were set to $0.5 \mathrm{~m} / \mathrm{sec}, 0.85 \mathrm{~m} / \mathrm{sec}$, or $1.15 \mathrm{~m} / \mathrm{sec}$. Flow velocity measurements obtained with the electromagnetic sensor were periodically cross referenced (Figure 3) with point sampling of current velocities using a $10 \mathrm{MHz}$ Acoustic Doppler Velocimeter (SonTek ADV ${ }^{\mathrm{T}}$, San Diego, CA). The maximum achievable flow velocity was limited by the dimensions of the flume and the power of the trolling motor. Power supply for the trolling motor came from a 12-Volt battery and included 2 fully charged batteries as backup.

\section{Fish species}

We first conducted a pilot study using larvae from fathead minnows (Pimephales promelas; laboratory reared at $\mathrm{ORNL}$ ) to test the experimental procedures outlined in this section. The subsequent full-scale blade-strike study used striped bass (Morone saxatilis), walleye/sauger hybrids (Stizostedion spp.), and crappie (Pomoxis spp.) at different life stages (larvae and juveniles) (Table 1). YOY ages were expressed as days post hatching (dph).

Striped bass is a commercially and recreationally important species. Being anadromous, striped bass are likely to encounter hydrokinetic devices in rivers, estuaries, and shallow coastal marine 


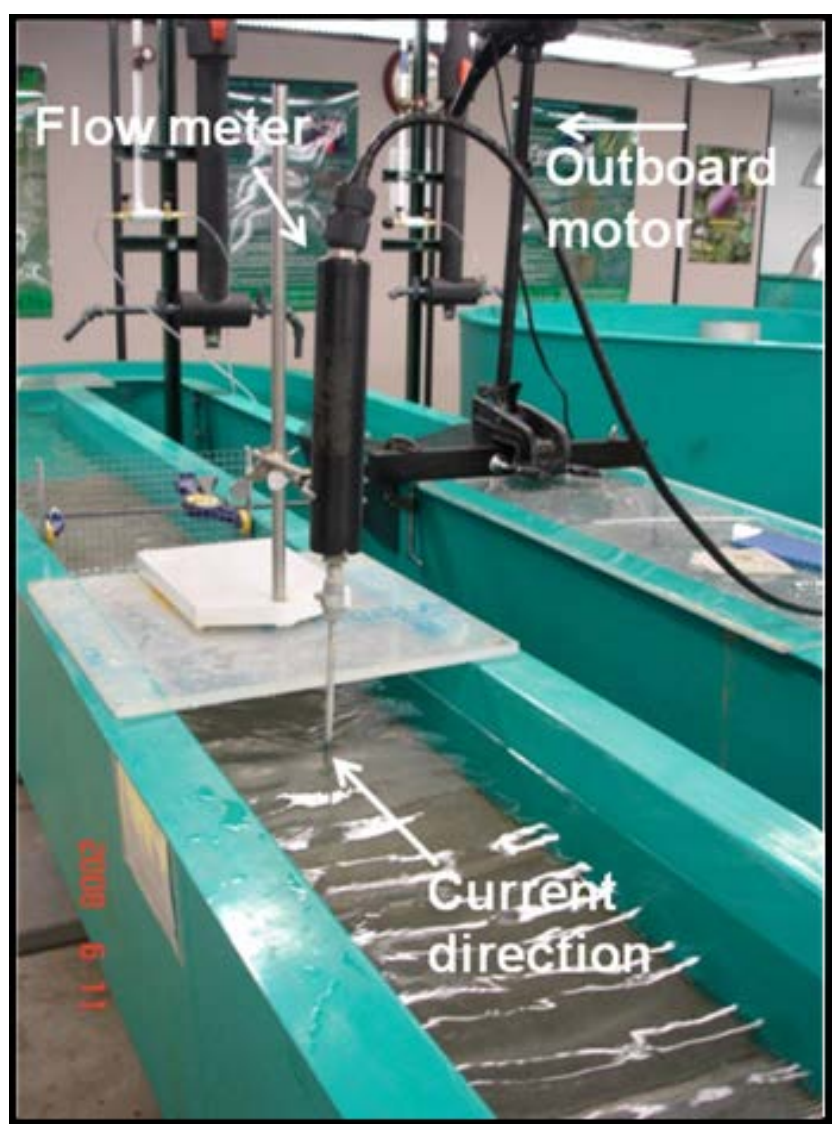

Figure 3. Circular flume setup showing outboard motor with propeller to create different flow velocities (background) and Acoustic Doppler Velocimeter (ADV) flow meter.

Table 1. Fish species with total length and age groups tested for mean percent survivorship following encounter at different flow velocities with contrasting rotor blade cross sections in circulating currents.

\begin{tabular}{|c|c|c|c|c|c|c|c|c|}
\hline \multirow{2}{*}{$\begin{array}{l}\text { Species } \\
\text { Striped bass }\end{array}$} & \multirow{2}{*}{$\begin{array}{l}\begin{array}{c}\text { Age } \\
\text { group } \\
\text { (dph) }\end{array} \\
1-3\end{array}$} & \multirow{2}{*}{$\begin{array}{l}\text { Total } \\
\text { length } \\
\text { (mm) }\end{array}$} & \multicolumn{3}{|c|}{$\begin{array}{l}\text { Current velocity } \\
\text { (meter/second) }\end{array}$} & \multicolumn{3}{|c|}{$\begin{array}{l}\text { Blade cross section profile } \\
\text { round pointed hydrofoil }\end{array}$} \\
\hline & & & 0.5 & - & - & 1 & 0 & 0 \\
\hline Striped bass & $11-14$ & $8.2-10.3$ & - & 0.85 & 1.15 & 1 & 1 & 1 \\
\hline Walleye/sauger & 30 & $30.2-34.8$ & 0.5 & - & - & 1 & 0 & 0 \\
\hline Crappie & 45 & $26.5-31.2$ & - & - & 1.15 & 1 & 0 & 1 \\
\hline Fathead minnow* & 21 & $12.8-14.1$ & - & - & 1.0 & 1 & 1 & 1 \\
\hline
\end{tabular}

*only tested at $1.0 \mathrm{~m} / \mathrm{sec}$ current velocities. 
waters. Walleye and sauger are popular freshwater game fishes that occur in lakes and ponds but prefer flowing water such as the large streams and rivers that will support hydrokinetic technology development. Crappies are abundant sport fish species that are widely distributed in North America, and occupy a range of habitats including large rivers. All of these fish species are abundant at adult life stages and are commonly distributed in the same environments that are proposed for HK power development.

Upon onset of the spring 2011 spawning season, fish larvae were periodically obtained from a local fish hatchery (Tennessee Wildlife Resources Agency's Eagle Bend Fish Hatchery in Clinton, TN) and held in 10- to 50-gallon aquaria for 24 to 48 hours for recovery from transport and acclimatization before exposure to experimental treatments.

\section{Experimental design and procedure}

The study was designed to test survivorship of fish following exposure to three contrasting rotor blade profiles, evaluated at conditions that included up to three different flow velocities. For each flow velocity $(0.5 \mathrm{~m} / \mathrm{sec}, 0.85 \mathrm{~m} / \mathrm{sec}$, and $~ 1.15 \mathrm{~m} / \mathrm{sec})$, six replicate runs with 15 YOY fish were examined, followed by six replicate runs as controls ('passage control' with the same flume injection and collection procedure, but with the blade profile removed). In addition, treatment and control groups were compared against a holding control where fish were held in separate groups only, but with no exposure to the flume currents or blade profiles to determine a rate of 'conditional or natural background' mortality. Hence, all results presented on survival/mortality rates were corrected for passage-control mortality and conditional (background) mortality. The minimum total required sample size per treatment of 90 was determined using power analysis and calculations to detect a large effect size (Cohen's $f=0.4$ ) at $\alpha=0.05$, with statistical power of the study equal or greater than $\beta=0.8$ (Cohen 1988). The selection of a large effect size reduced the minimum total required sample size per treatment and reduced the influence of variation in natural mortality in fish early life stages when comparing treatment groups against control groups.

A conceptual flowchart to derive sample sizes and the number of treatments is shown in Figure 4.

For treatment and controls, YOY fish (15 at a time) were poured with a funnel into the vinyl tubing. The fish exited the tubing into the flow moving toward the leading edge of the blade with some initial velocity to minimize shear stresses at the point of entrance into the flume. A simplified version of Bernoulli's equation (Sturm 2010) was used to calculate the necessary head for matching the fish introduction velocity with the velocity of the circulating current as defined for the test condition. 


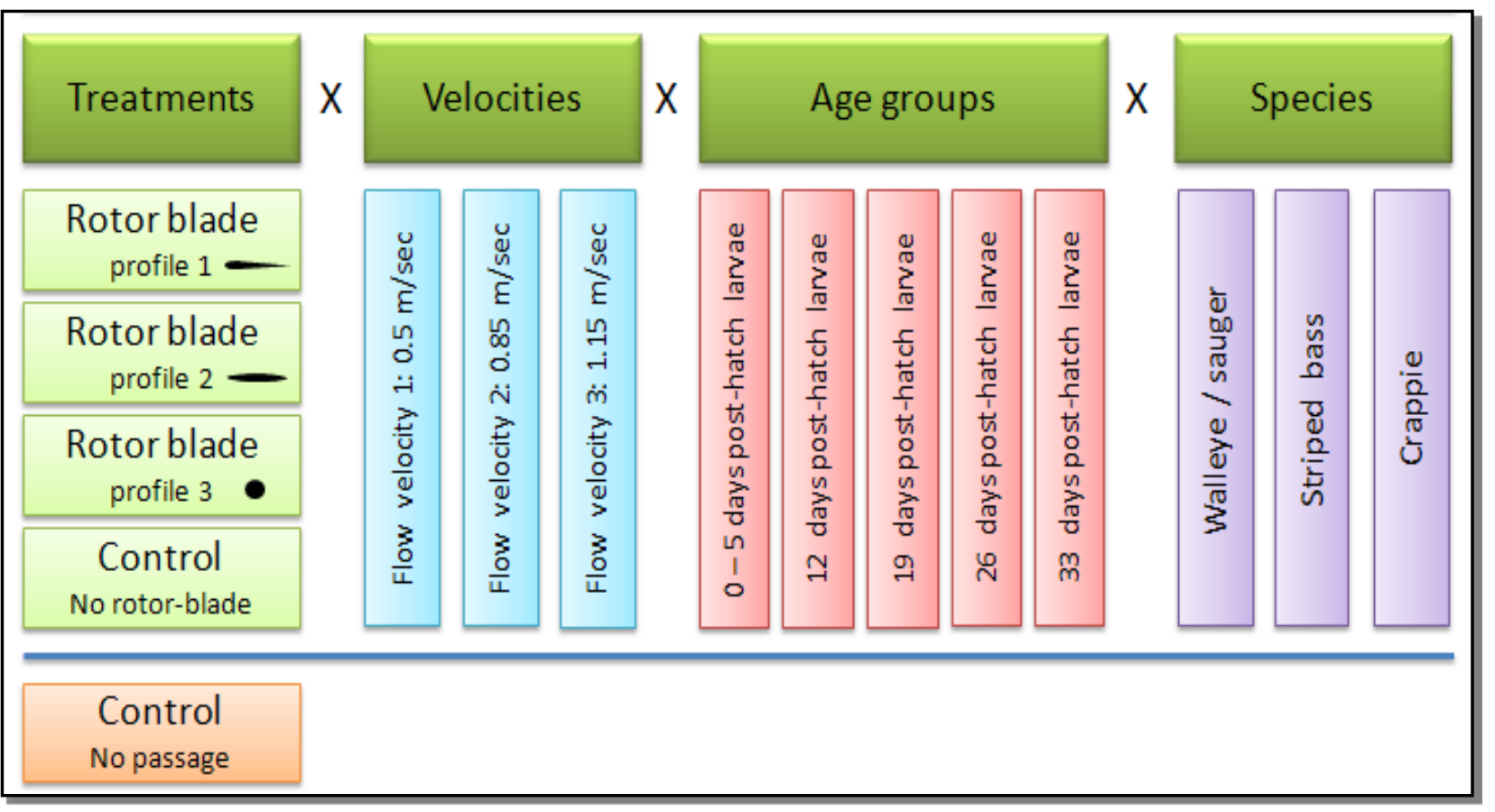

Figure 4. Conceptual flowchart used to derive number of treatments and calculation of minimum sample size needed. Note: not all age groups were available for experimental treatment.

Fish introduced into the flume were swept by the circulating currents toward the leading edge of the blade profile, approximately 2 blade diameters downstream. Immediately following transport past the blade profile, fish were recaptured using fine-mesh dip nets, gently transferred from the circulating-flow water channel to small holding tanks, and visually assessed for damage and mortality. After 1 hour, 3 hours and 24 hours post passage, the holding control, passage control, and passage treatment replicates were examined again to determine delayed mortality from entrainment and rotor blade profile passage. Visual observations indicated that healthy fish larvae swim in short bursts of one to two seconds duration, followed by a short period of rest and by movement patterns characterized by multiple directional changes. Fish larvae were considered injured or morbid (fatally injured) if they displayed unusual swimming movements such as weak but persistent posterior body undulations with propulsion in a circular path in the uppermost water column. Larvae that showed only minimal movement or no movement during visual observation over a period of 30 to 60 seconds at time 3 and 24 hours post passage were considered as injured or morbid. At 24 hours post passage, morbid larvae were considered non-surviving. When alive, early life stage fish larvae are almost transparent, but immediate onset of protein degradation upon death turned the larvae opaque and white. Dead fish were removed from the holding tanks as detected. 


\section{Data analyses}

Results were expressed as percent survivorship by species, age groups, and treatments. Survivorship was calculated as the percent of fish alive after 24 hours following experimental procedure (treatment or control). Conditional mortality for times 1, 3, and 24 hours post treatment was calculated by subtracting the percent survivorship in 'holding' replicates from the value 100 (indicating $0 \%$ pre-treatment mortality). Mortalities from the passage treatment $\left(\mathrm{M}_{P_{t}}\right)$ with entrainment and rotor blade encounter were calculated using equation 1,

$$
\left.\left.M_{P t}=\left(100-P_{S p t}\right)-P_{C M}\right)\right)
$$

where 100 represents the initial percent alive of the YOY for each replicate, $\mathrm{P}_{\text {Spt }}$ is the percent survivorship from passage treatments, and $\mathrm{P}_{C M}$ is the percent conditional mortality, derived by equation 2.

$$
P_{C M}=(100-\text { percent mean survivorship of YOY in the holding control). }
$$

The calculation of percent mortality for the passage control (that passed through the flume and YOY were collected, but without exposure to blade profiles), with consideration of conditional mortality allowed the assessment of percent mortality likely attributable to effects associated with blade exposure. Delayed treatment mortalities were calculated as the difference in mean treatment mortality at times 3 and 24 hours post blade passage, minus the conditional mortality.

\section{Results}

\section{Striped bass yolk-sac larvae 1 day post hatching (dph)}

The earliest life-stage fish tested in the circulating flow current were striped bass yolk-sac larvae at age one dph. Unfortunately, high yolk-sac larvae mortality during the pre-experiment acclimation period prevented inclusion of replicate treatments for YOY age one dph. The surviving larvae were divided into three groups (holding control $(n=20)$, passage control $(n=25)$, and passage treatment $(n=29))$. Hence, a total of 74 striped bass larvae of age $1 \mathrm{dph}$ were tested.

Percent survival decreased with time after the experimental exposure for all 3 groups (Figure 5). The highest mortality among the passage treatment group occurred soon after exposure to the circular blade profile and flume; mortality in this group was over 70 percent after one hour, and continued to increase over the 24-hour holding period. Most of the mortality in the passage control group also occurred in the first hour after exposure to the flume, although survivorship changed little subsequently. 


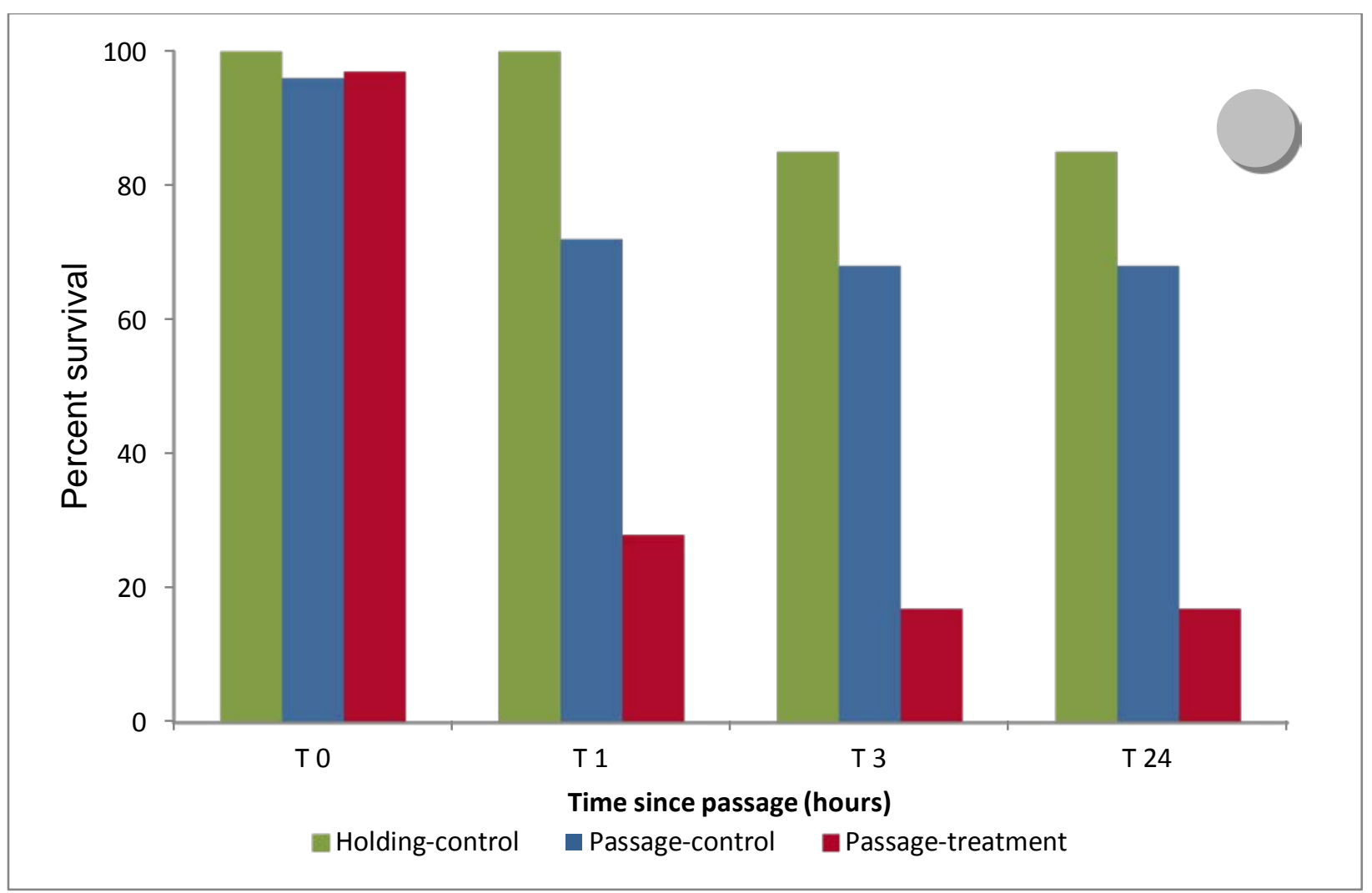

Figure 5. Striped bass survivorship among earliest life-stage (1 day post-hatching) exposed to passage by a 4.0-centimeter-diameter cylinder profile in a $0.5 \mathrm{~m} / \mathrm{sec}$ velocity current. Conditional mortality at time 24 hours post passage $\left(T_{24}\right)$ was 15.0 percent, with 17.2 percent larval survival in the passage-treatment and 68.0 percent in the passage-control, respectively.

The mean survivorship after 24 hours post testing was 85 percent for the holding control, 68 percent for the passage control and only 17 percent for the passage treatment following passage by a circular shape blade profile (cylinder) at a velocity of $0.5 \mathrm{~m} / \mathrm{sec}$ (Table 2). Mean treatment survival at one hour post treatment was $28 \%$. Conditional mortality in the holding control group reached $15 \%$ at 3 hours post passage $\left(T_{3}\right)$ and remained at that level until time 24 hours post passage (Figure 5), while treatment mortality (corrected for control mortality) increased to $67.8 \%$ by 24 hours post passage $\left(T_{24}\right)$. In the passage control the mortality rate was $17.0 \%$ at time 24 hours post treatment. It must be noted that these data were deemed of exploratory nature only, because results from the striped bass age $1 \mathrm{dph}$ tests lacked sufficient replication to allow for the examination of variation among treatments. 
Table 2. Mortality rates for striped bass early-life stages ( $1 \mathrm{dph}$ ) after encounter of a cylindrical rotor cross section in $0.5 \mathrm{~m} / \mathrm{sec}$ current velocity.

\begin{tabular}{|c|c|}
\hline $\begin{array}{c}\text { Striped bass } \\
\text { in } 0.5 \mathrm{~m} / \mathrm{sec} \text { flow velocity }\end{array}$ & $\begin{array}{l}\text { Rotor blade cross section profile } \\
\text { Round }\end{array}$ \\
\hline Survivorship in background control ( $\%$ ) at $\mathrm{T}_{24}$ & 85.0 \\
\hline Survivorship in treatment control (\%) at $\mathrm{T}_{24}$ & 68.0 \\
\hline Survivorship in treatment (\%) at $T_{24}$ & 17.0 \\
\hline Conditional mortality (\%) at $T_{24}$ & 15.0 \\
\hline Treatment mortality (\%) at $\mathrm{T}_{24}$ & 67.8 \\
\hline Mortality (\%) in control at $\mathrm{T}_{24}$ & 17.0 \\
\hline Mortality (\%) from treatment effect at $T_{24}$ & 50.8 \\
\hline Delayed mortality $\quad(\%)$ at $\mathrm{T}_{3}$ & 64.3 \\
\hline Delayed mortality $\quad(\%)$ at $\mathrm{T}_{24}$ & 35.8 \\
\hline
\end{tabular}

\section{Striped bass age 11 to 14 days post hatching}

Survivorship following blade encounter was examined for striped bass post-yolk-sac larvae aged $11 \mathrm{dph}$ to $14 \mathrm{dph}$ using all of the three blade profiles and for flow velocities of $0.85 \mathrm{~m} / \mathrm{sec}$ and $1.15 \mathrm{~m} / \mathrm{sec}$. For both flow regimes, these experiments included three replicates for holding control and six replicates each for passage control and passage treatments, with sample size $n=15$ per replicate.

Figures 6 to 8 illustrate the mean survival rates of striped bass larvae following blade passage in currents of $0.85 \mathrm{~m} / \mathrm{sec}$ velocity. Immediate survival rates for YOY exposed to blade passage at $0.85 \mathrm{~m} / \mathrm{sec}$ flow velocity ranged from $97.1 \%$ to $98.8 \%$ with no significant difference among treatments (Table 3). Mean survival of all test and control groups declined throughout the 24-hour post-test holding period, with lowest survivals generally occurring in the passage treatment groups that were exposed to the blade profiles. Among the 3 blade profiles tested, the hydrofoil passage treatment group had the highest survival rate for YOY at time 3 hours $($ mean $=78.4 \%$, ST.D. $=15.7 \%)$, and at time 24 hours (mean $=66.5 \%$, ST.D. $=19.5 \%)$. The lowest mean treatment survival $(47.0 \%)$ at time 24 post treatment was observed for the pointed blade profile (Table 3; Figure 8). 


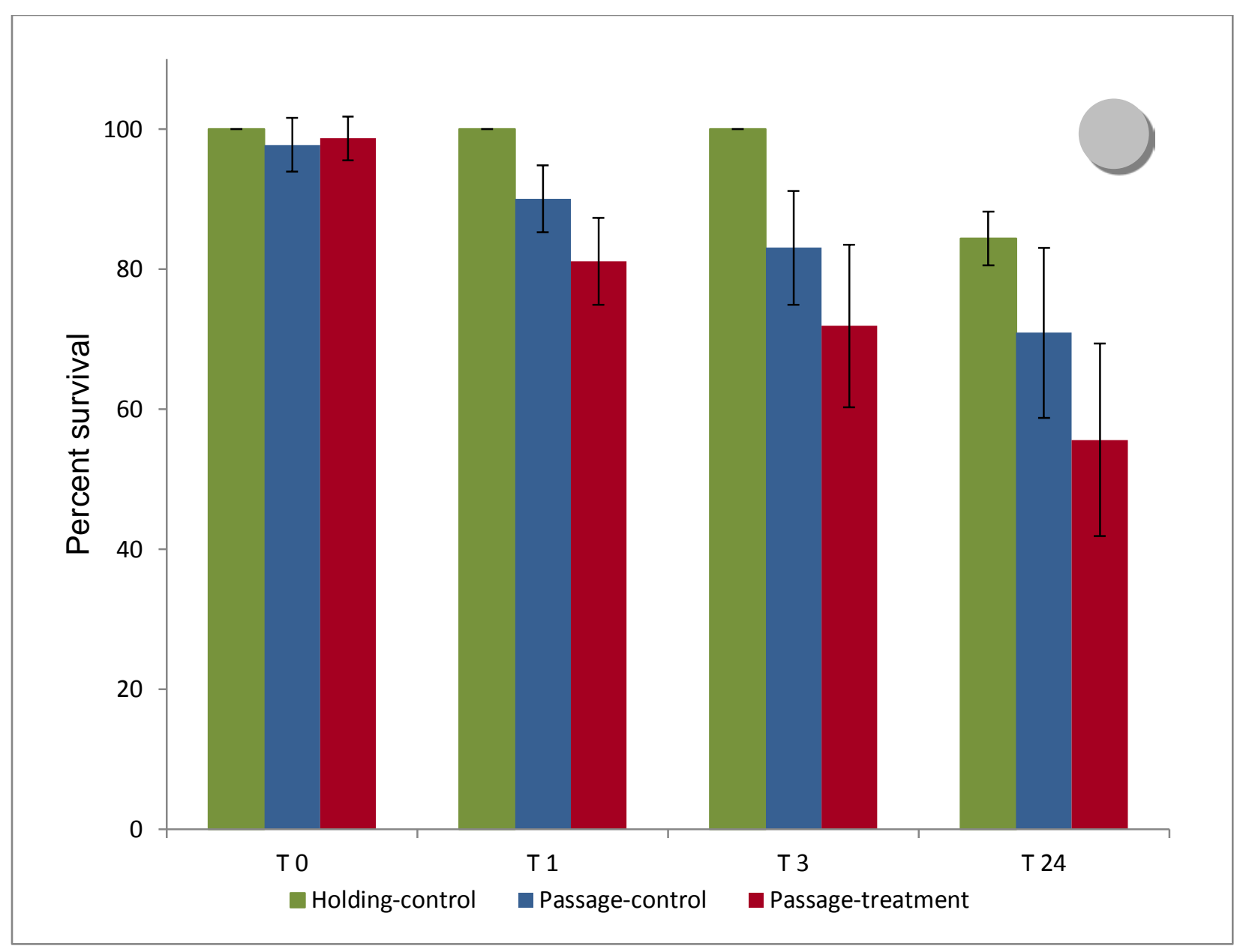

Figure 6. Percent survival for striped bass aged 11-14 days post-hatching after exposure to a round (cylindrical) blade profile in a $0.85 \mathrm{~m} / \mathrm{sec}$ current. 


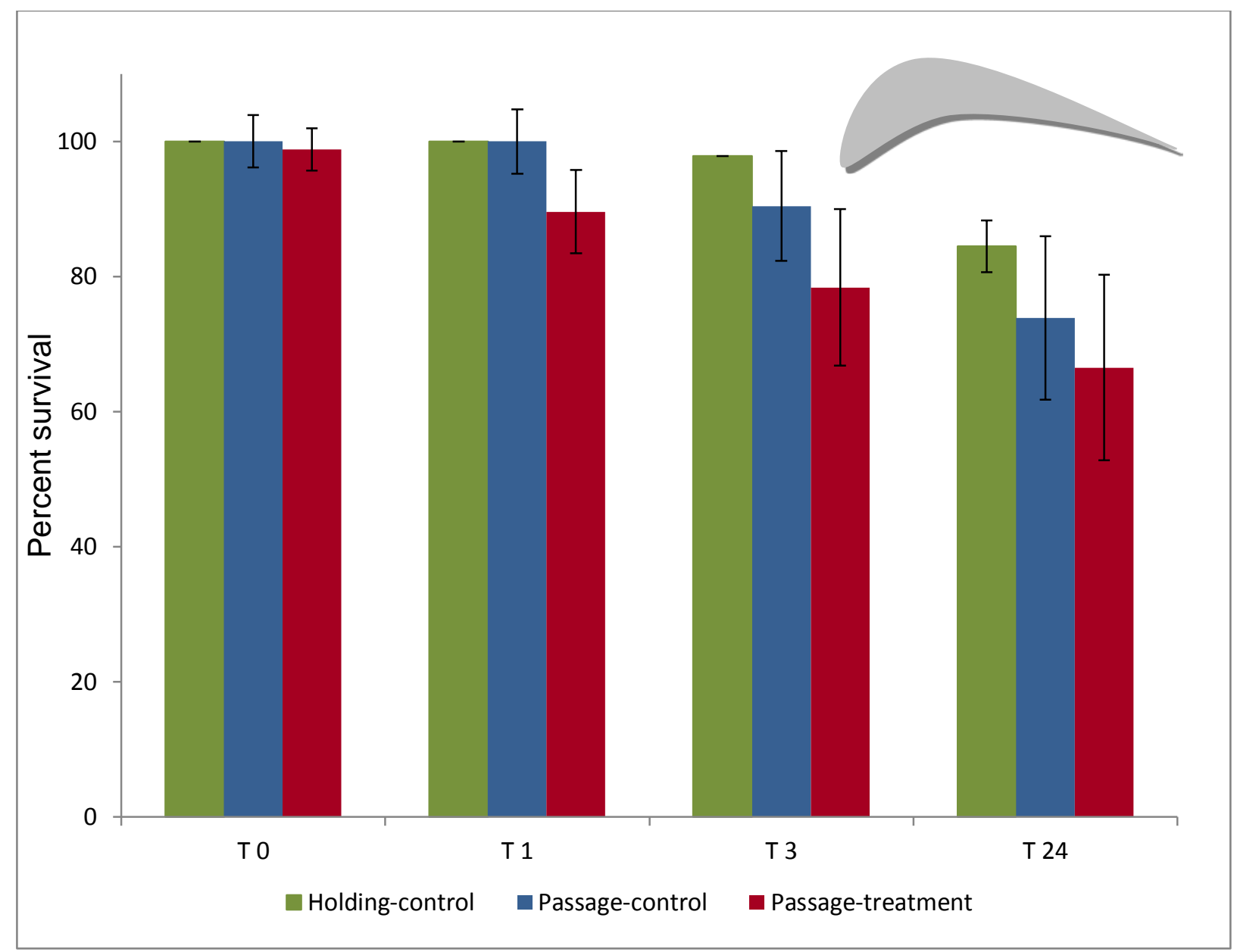

Figure 7. Percent survival for striped bass aged 11-14 days post-hatching after exposure to a hydrofoil-shaped blade profile in a $0.85 \mathrm{~m} / \mathrm{sec}$ current. 


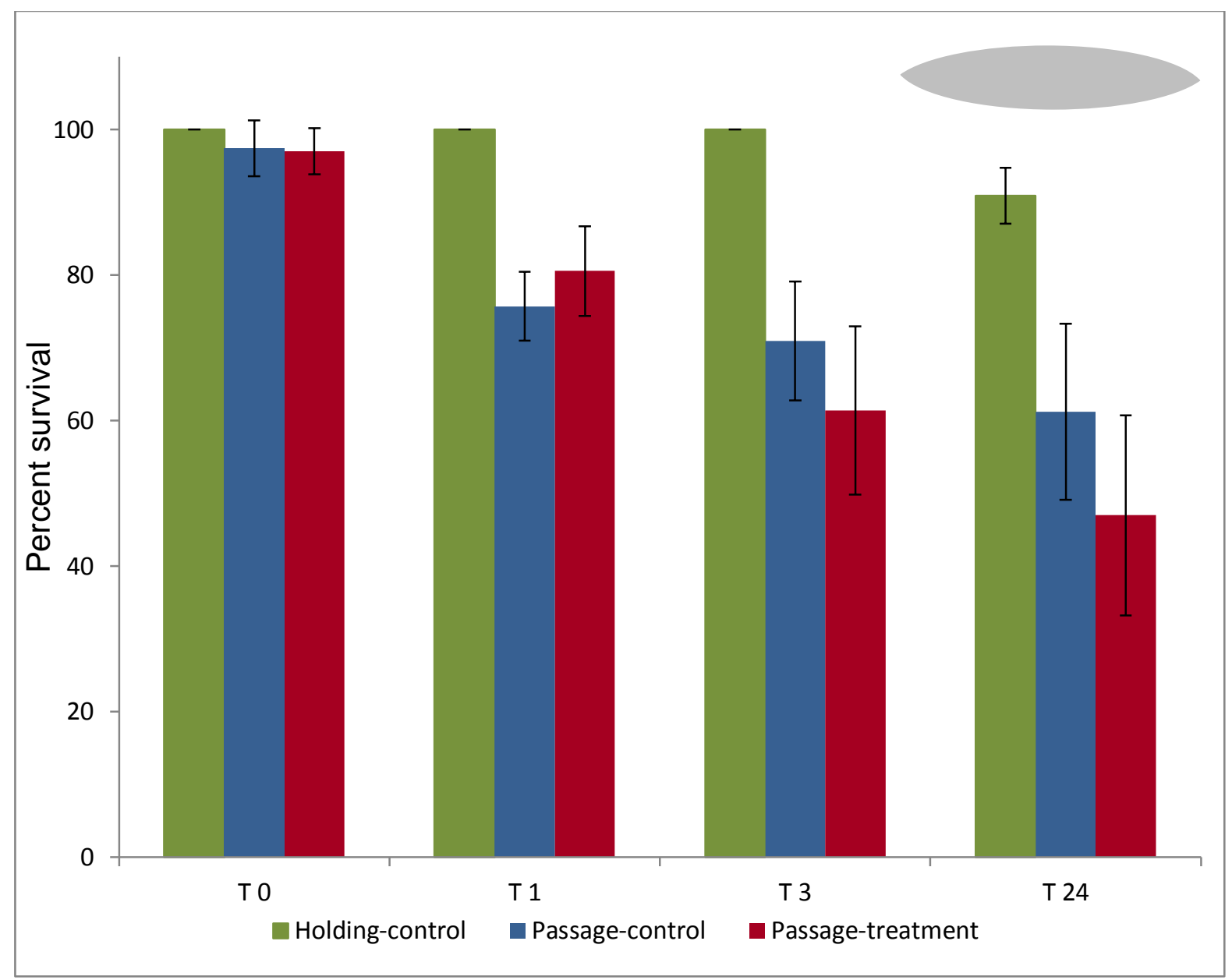

Figure 8. Percent survival for striped bass aged 11-14 days post-hatching after exposure to a pointed blade profile in a $0.85 \mathrm{~m} / \mathrm{sec}$ current. 
Table 3. Mortality rates for striped bass early-life stages (11-14 dph) in $0.85 \mathrm{~m} / \mathrm{sec}$ current and encounter with different shapes for rotor blade cross sections.

\begin{tabular}{|c|c|c|c|}
\hline Striped bass & \multicolumn{3}{|c|}{ Rotor blade cross section profile } \\
\hline in $0.85 \mathrm{~m} / \mathrm{sec}$ flow velocity & Round & Hydrofoil & Pointed \\
\hline Mean Immediate treatment survival rate at $T_{0}$ & 98.7 & 97.1 & 98.8 \\
\hline Mean treatment survival rate at $T_{3}$ & 71.9 & 78.4 & 61.4 \\
\hline Mean treatment survival rate at $\mathrm{T}_{24}$ & 55.6 & 66.5 & 47.0 \\
\hline Conditional mortality (\%) at $\mathrm{T}_{24}$ & 15.6 & 15.6 & 9.0 \\
\hline Treatment mortality (\%) at $\mathrm{T}_{24}$ & 28.8 & 17.9 & 43.9 \\
\hline Mortality (\%) in control at $\mathbf{T}_{24}$ & 13.5 & 10.6 & 29.7 \\
\hline Mortality (\%) from treatment effect at $T_{24}$ & 15.3 & 7.3 & 14.2 \\
\hline Delayed mortality $\quad(\%)$ at $\mathrm{T}_{3}$ & 26.8 & 18.2 & 35.6 \\
\hline Delayed mortality $\quad(\%)$ at $\mathrm{T}_{24}$ & 0.7 & -3.7 & 5.4 \\
\hline
\end{tabular}

$\mathrm{T}=$ treatment, lower case numbers indicate hours post treatment.

Figures 9 to 11 display the mean survival of striped bass larvae exposed to 3 different blade profiles at $1.15 \mathrm{~m} / \mathrm{sec}$ velocity. Mean survival declined in all groups throughout the 24 hour post-test holding period, but especially among the flume-exposed fish (i.e., the passage control and passage treatment groups); survival in the holding control groups remained relatively high. The largest passage treatment mortality at 24 hours post-test was observed for YOY that passed the round blade profile; the treatment mortality of this group at $\mathrm{T}_{24}$ was $67.0 \%$ (Table 4). Immediate survival rates for YOY were lowest from the pointed blade treatment (mean = $95.6 \%, S T . D .=5.4 \%$ ) but overlap in error bars indicated no significant differences from the immediate survival rates of the two control groups (Figure 11). The lowest conditional mortality (2.2\%) was observed among fish exposed to the round blade profile, but this coincided with the largest mortality rates for treatments and controls (Table 4; Figure 9). In currents with $1.15 \mathrm{~m} / \mathrm{sec}$ velocity, delayed mortality rates for striped bass post-yolk-sac larvae were lowest from exposures to the pointed blade profile (Table 4; Figure 11). 


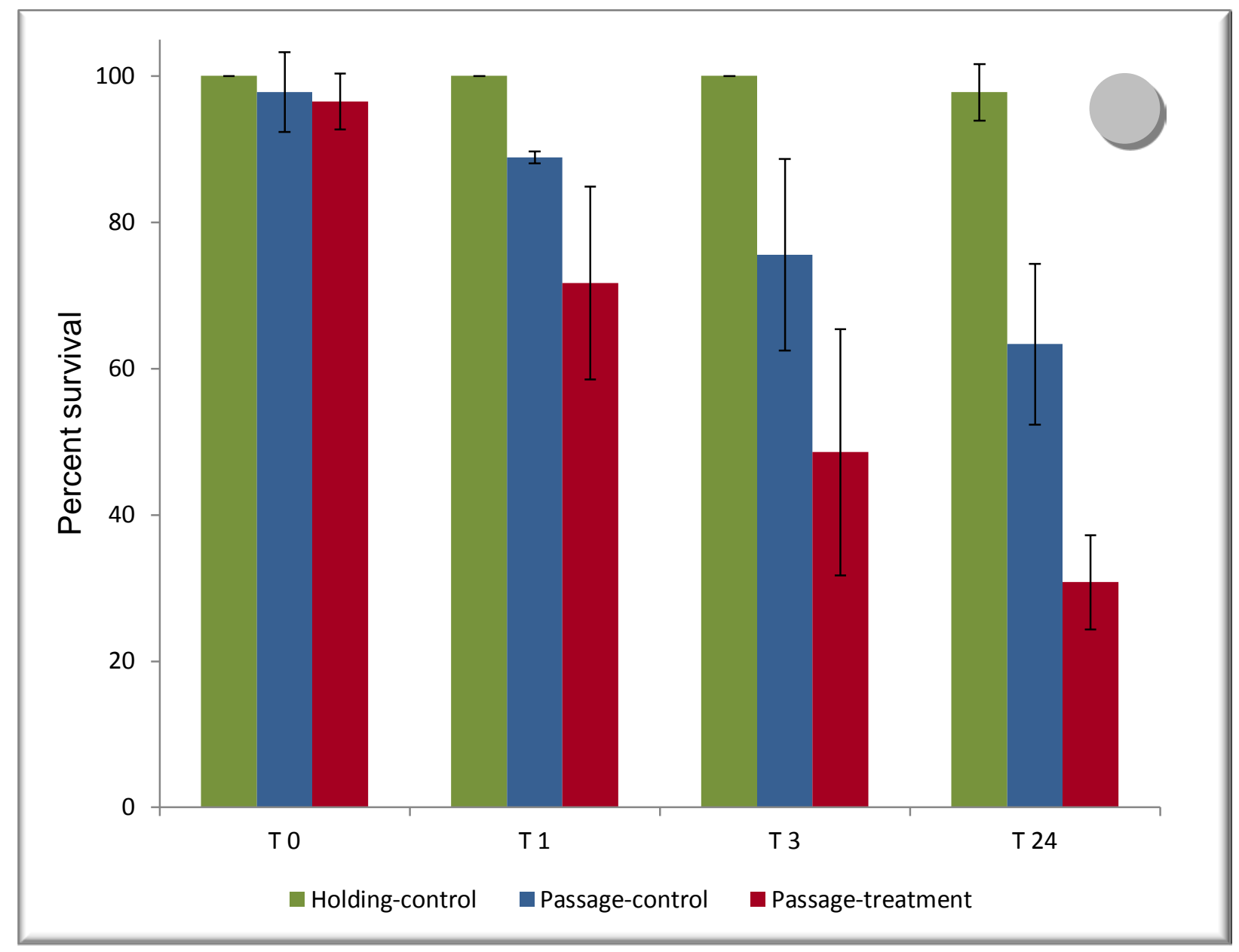

Figure 9. Percent survival for striped bass aged 11-14 days post-hatching after exposure to a round (cylindrical) blade profile in a $1.15 \mathrm{~m} / \mathrm{sec}$ current. 


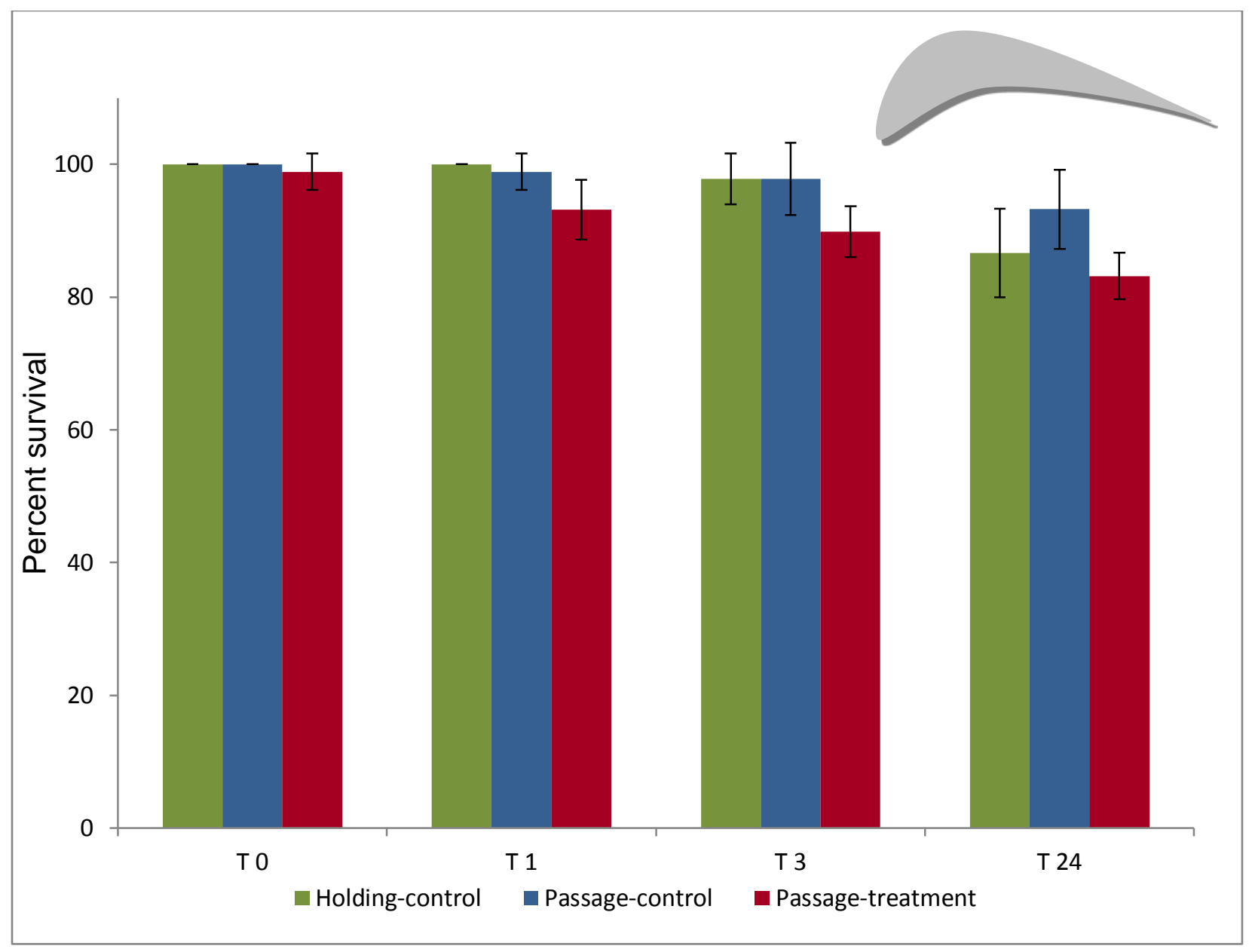

Figure 10. Percent survival for striped bass aged 11-14 days post-hatching after exposure to a hydrofoil-derived blade profile in a $1.15 \mathrm{~m} / \mathrm{sec}$ current. 


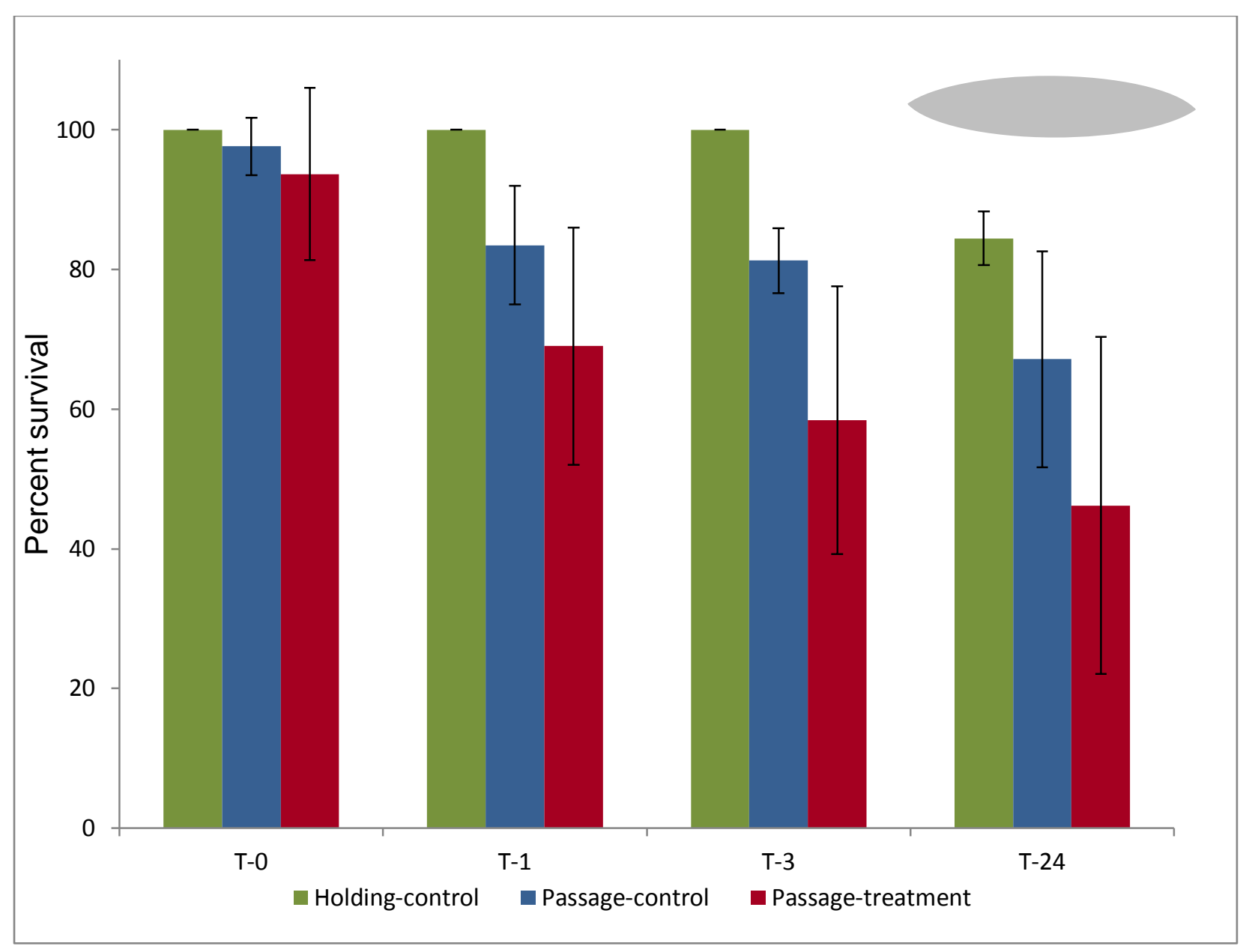

Figure 11. Percent survival for striped bass at age 11-14 days post-hatching after exposure to a pointed blade profile in a $1.15 \mathrm{~m} / \mathrm{sec}$ current. 
Table 4. Mortality rates for striped bass post-yolk-sac larvae (11 - $14 \mathrm{dph})$ in $1.15 \mathrm{~m} / \mathrm{sec}$ current and encounter with different shapes for rotor blade cross sections.

\begin{tabular}{|c|c|c|c|}
\hline Striped bass & \multicolumn{3}{|c|}{ Rotor blade cross section profile } \\
\hline in $1.15 \mathrm{~m} / \mathrm{sec}$ flow velocity & Round & Hydrofoil & Pointed \\
\hline Mean Immediate treatment survival rate at $\mathrm{T}_{0}$ & 96.5 & 97.8 & 95.6 \\
\hline Mean treatment survival rate at $T_{3}$ & 48.6 & 74.4 & 65.6 \\
\hline Mean treatment survival rate at $T_{24}$ & 30.8 & 52.2 & 46.7 \\
\hline Conditional mortality (\%) at $\mathrm{T}_{24}$ & 2.2 & 8.9 & 17.8 \\
\hline Treatment mortality (\%) at $\mathrm{T}_{24}$ & 67.0 & 38.9 & 35.6 \\
\hline Mortality (\%) in control at $T_{24}$ & 34.4 & 29.6 & 19.4 \\
\hline Mortality (\%) from treatment effect at $T_{24}$ & 32.5 & 9.3 & 16.2 \\
\hline Delayed mortality $\quad(\%)$ at $\mathrm{T}_{3}$ & 47.9 & 23.3 & 21.1 \\
\hline Delayed mortality $\quad(\%)$ at $\mathrm{T}_{24}$ & 15.6 & 13.3 & 1.1 \\
\hline
\end{tabular}

$\mathrm{T}=$ treatment, lower case numbers indicate hours post treatment.

\section{Walleye/sauger age 30 days post hatching}

Because only a limited number of walleye/sauger YOY were available, these fish were tested in the circulating current at a single velocity $(0.5 \mathrm{~m} / \mathrm{sec})$ and a single blade profile (round). The data presented were derived from one control holding, one control passage and three treatment replicates with sample size $n=10$ per replicate.

Walleye/sauger of age 30 days post hatching were highly mobile and were observed successfully avoiding contact with the blade profile. Survival rates of YOY walleye at $\mathrm{T}_{24}$ were $100 \%$ for all control and test groups over the 24-hour post-test holding period (Figure 12, Table 5). Consequently, the conditional mortality of walleye/sauger juveniles exposed to a cylindrical rotor blade profile under these conditions was $0 \%$. Further testing with walleye YOY was discontinued because no younger age classes were available at that time and the faster current velocities necessary to gain additional insight from experimental procedure using the $30 \mathrm{dph}$ age cohort could not be accommodated by the dimensions of the test flume. 


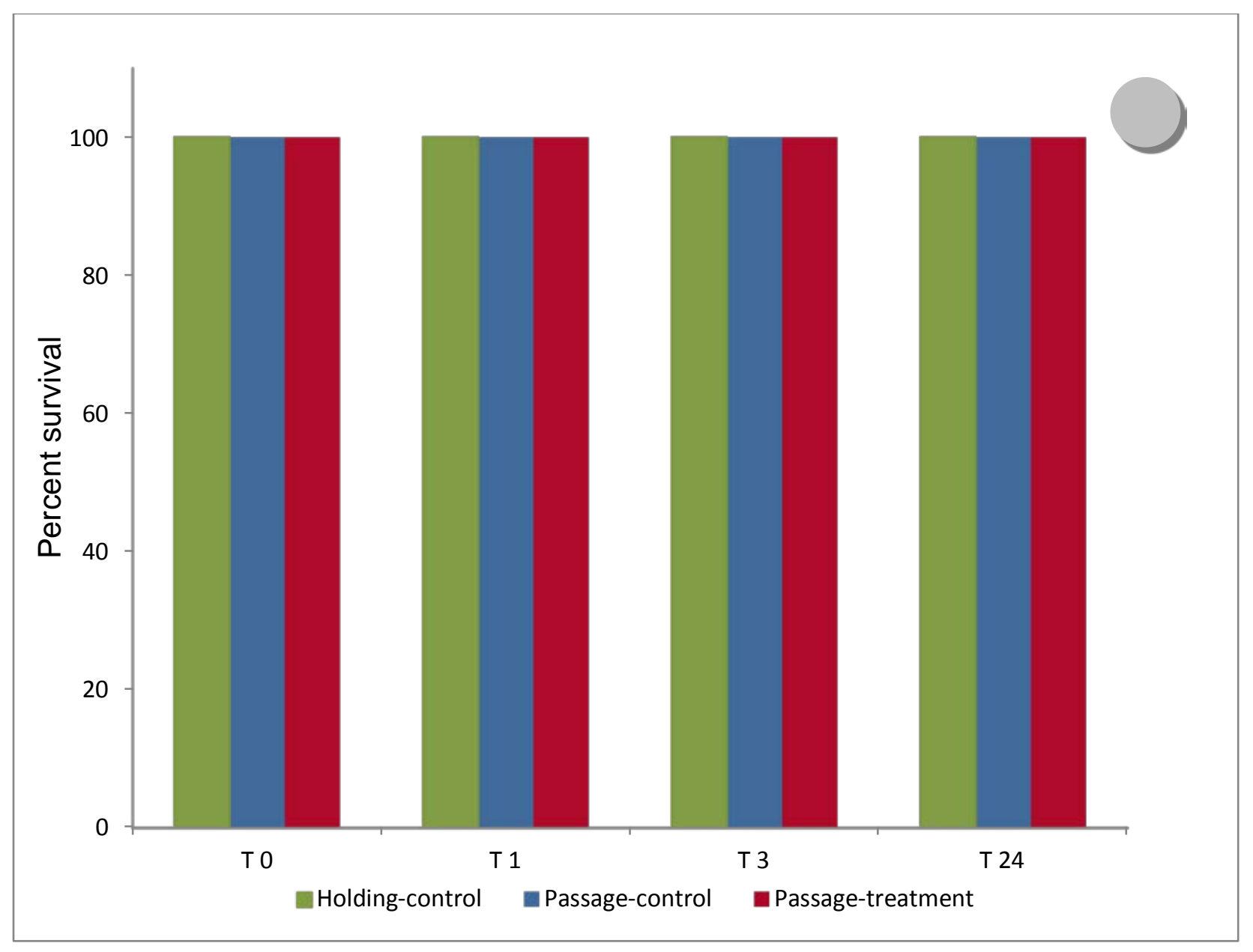

Figure 12. Survival of walleye/sauger (age 30 days post hatching) upon blade encounter in currents of $0.5 \mathrm{~m} / \mathrm{sec}$ velocity. The $\mathrm{Y}$-axis indicates survival rate expressed in percent, the $\mathrm{X}$-axis indicated time in hours past exposure to the blade profile in a $0.5 \mathrm{~m} / \mathrm{sec}$ current. 
Table 5. Survival rates for walleye/sauger age 30 days post hatching, in $0.5 \mathrm{~m} / \mathrm{sec}$ current velocity and exposure to round (cylindrical) blade cross section.

\begin{tabular}{|c|c|}
\hline $\begin{array}{c}\text { Walleye/sauger } \\
\text { in } 0.5 \mathrm{~m} / \mathrm{sec} \text { flow velocity }\end{array}$ & $\begin{array}{l}\text { Rotor blade cross section profile } \\
\text { Round }\end{array}$ \\
\hline Survivorship in background control (\%) at $\mathrm{T}_{24}$ & 100 \\
\hline Survivorship in treatment control (\%) at $\mathrm{T}_{24}$ & 100 \\
\hline Survivorship in treatment (\%) at $\mathrm{T}_{24}$ & 100 \\
\hline Conditional mortality (\%) at $T_{24}$ & 0 \\
\hline Treatment mortality (\%) at $\mathrm{T}_{24}$ & 0 \\
\hline Mortality (\%) in control at $\mathrm{T}_{24}$ & 0 \\
\hline Mortality (\%) from treatment effect at $T_{24}$ & 0 \\
\hline Delayed mortality $\quad(\%)$ at $T_{3}$ & 0 \\
\hline Delayed mortality $\quad(\%)$ at $\mathrm{T}_{24}$ & 0 \\
\hline
\end{tabular}

$\mathrm{T}=$ treatment, lower case numbers indicate hours post treatment.

\section{Crappie age 45 days post hatching}

The tests with crappie were limited by the availability of YOY of similar size, and as a result the data included here were collected for exploratory purposes only. Three replicates with 15 fish each were exposed to round or hydrofoil-shape blade profiles at a velocity of $0.85 \mathrm{~m} / \mathrm{sec}$. No apparent effects were detected for encounter with either of the rotor blade shapes; immediate survival and survivals at 1 and 3 hours post treatment were $100 \%$ for all treatment and replicates (Figure 13, Table 6). The survival rates at $T_{24}$ were $100 \%$ for juvenile crappie exposed to the round blade profile, and $97.7 \%$ for crappie exposed to the hydrofoil (Figure 13). The absence of a holding control group for calculating conditional mortality in these trials with crappie precluded further interpretation of the data, but the high survivals of juvenile crappie exposed to the circulating flume with rotor blade profiles suggest that conditional mortalities would have been similar to the actual observed mortalities. 


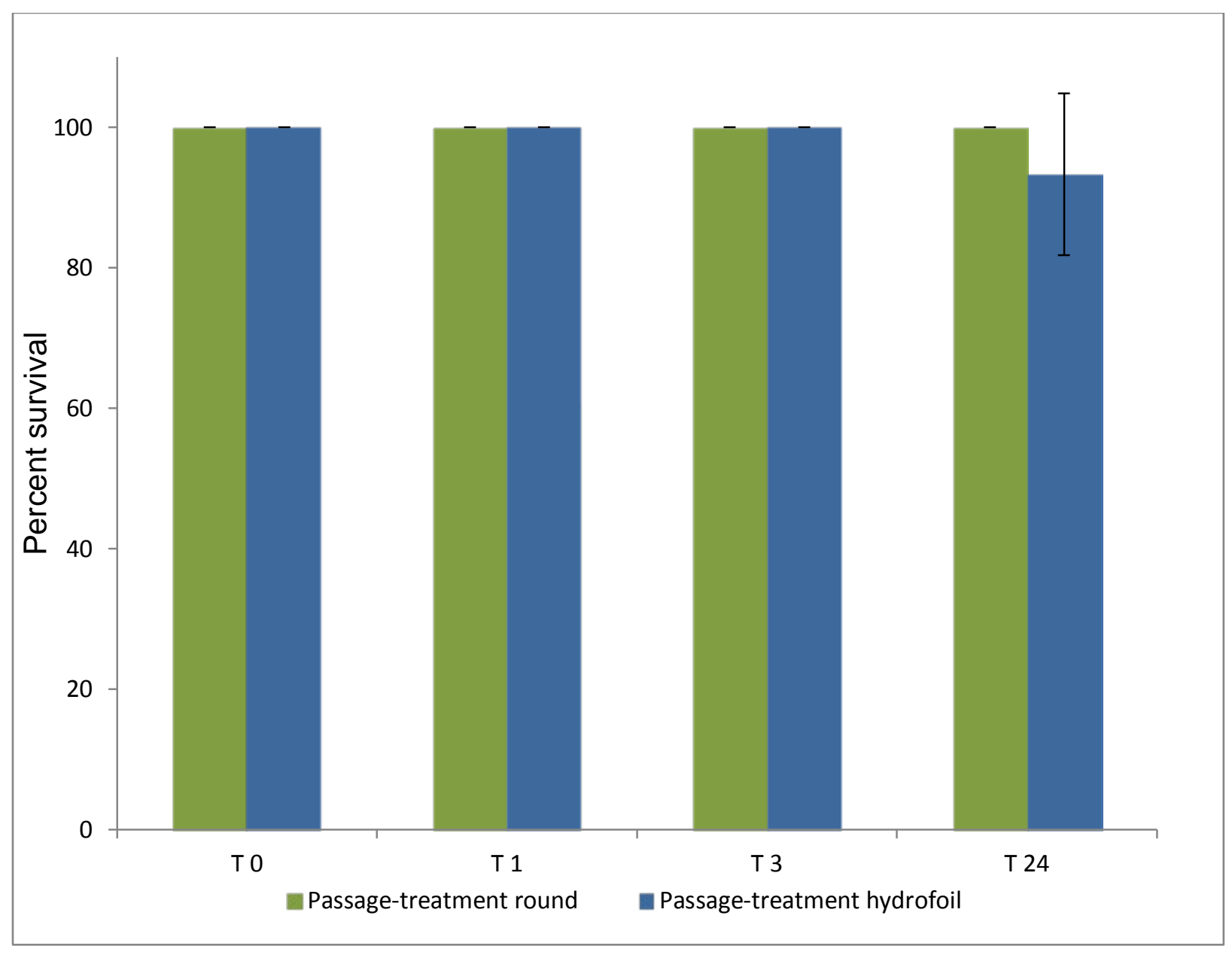

Figure 13. Percent survival of crappies (age 45 days post hatching) following blade encounter in currents of $0.85 \mathrm{~m} / \mathrm{sec}$ velocity. Passage-treatment round indicates exposure to a round blade profile (treatment mortality $=0 \%$ ); Passage-treatment hydrofoil indicates exposure to the hydrofoil rotor shape (treatment mortality $=2.1 \%$ ). Note: data for Holding-control and Passage-control were not collected due to small numbers of available fish. 
Table 6. Survival rates for crappie aged 45 days post hatching, in $1.15 \mathrm{~m} / \mathrm{sec}$ current velocity and exposure to different rotor blade currents in circulating currents.

\begin{tabular}{|c|c|c|}
\hline Crappie & \multicolumn{2}{|c|}{ Rotor blade cross section proffle } \\
\hline in $1.15 \mathrm{~m} / \mathrm{sec}$ flow velocity & Round & Hydrofoil \\
\hline Survivorship in background control ( $\%$ ) at $\mathrm{T}_{24}$ & - & - \\
\hline Survivorship in treatment control (\%) at $\mathrm{T}_{24}$ & - & - \\
\hline Survivorship in treatment (\%) at $T_{24}$ & 100 & 97.8 \\
\hline Conditional mortality (\%) at $\mathrm{T}_{24}$ & - & - \\
\hline Treatment mortality (\%) at $\mathrm{T}_{24}$ & 0 & 2.2 \\
\hline Mortality (\%) in control at $\mathrm{T}_{24}$ & - & - \\
\hline Mortality (\%) from treatment effect at $T_{24}$ & 0 & 2.2 \\
\hline Delayed mortality $\quad(\%)$ at $T_{3}$ & 0 & 0 \\
\hline Delayed mortality $\quad(\%)$ at $\mathrm{T}_{24}$ & 0 & 2.2 \\
\hline
\end{tabular}

$\mathrm{T}=$ treatment, lower case numbers indicate hours post treatment.

\section{Fathead minnow age cohort 21 to 30 days post hatching}

The survivals of juvenile fathead minnows (age cohort 21 to 30 days post hatching) were quantified following encounter with the three blade profiles in a current velocity of $1.0 \mathrm{~m} / \mathrm{sec}$. The results were derived from experimental procedures using 3 replicates for holding control, and 6 replicates each for passage control and passage treatments for blade profiles, with sample size $n=15$ per replicate. Mean treatment survival rates at $T_{24}$ ranged from $85.6 \%$ for encounter with the round blade profile to $91.1 \%$ for encounter with the pointed blade profile (Figure 14, Table 7). Treatment mortality at $\mathrm{T}_{24}$ was greatest for minnows that encountered the round blade profile $(12.2 \%$, versus $5.6 \%$ from exposure to the pointed blade and $5.6 \%$ from exposure to the hydrofoil; Table 7). 


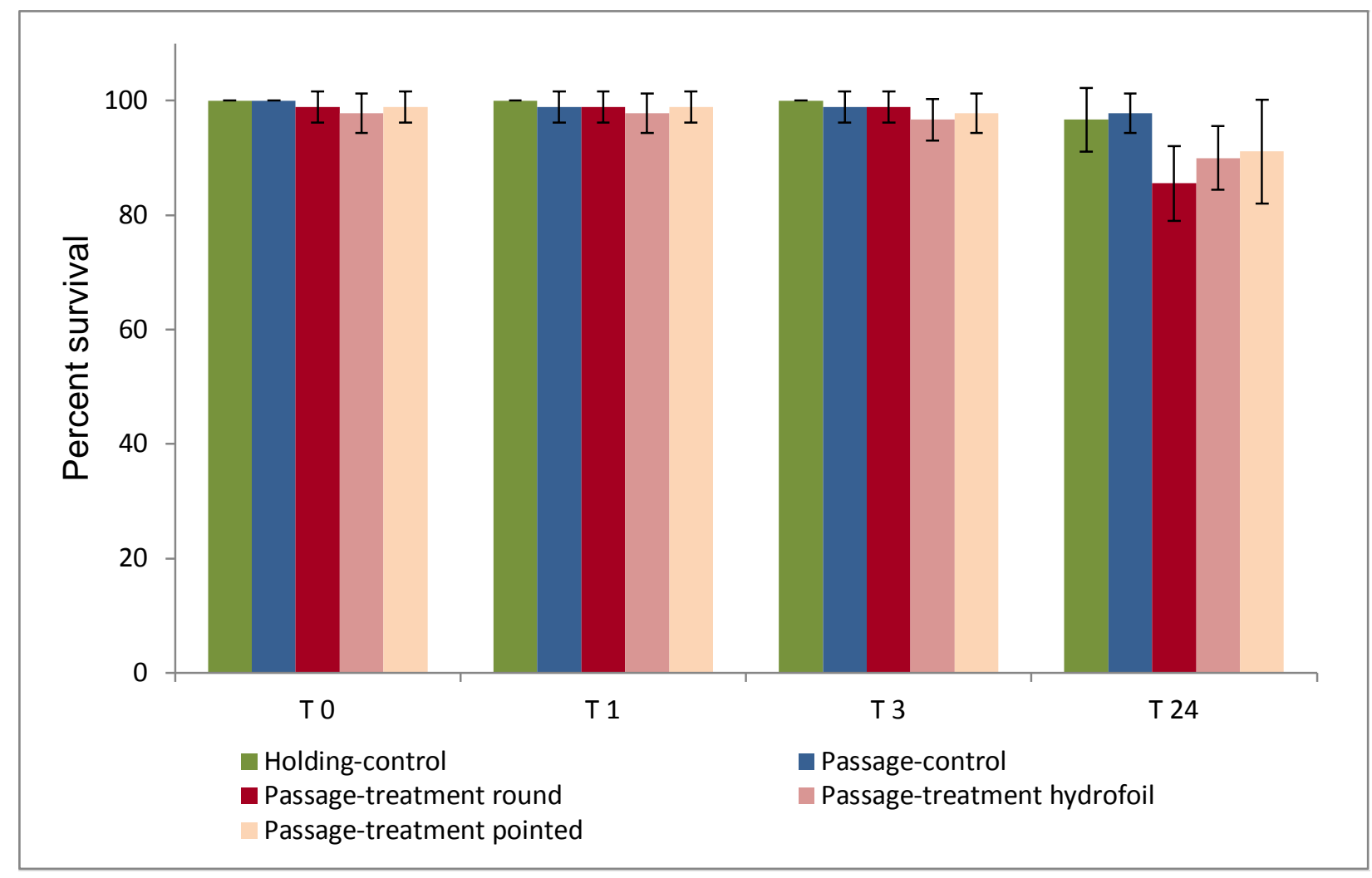

Figure 14. Percent survival for fathead minnow (age cohort 21 - 30 days post hatching) upon exposure to different blade cross section profiles in currents with $1.0 \mathrm{~m} / \mathrm{sec}$ velocity.

Table 7. Mortality rates for fathead minnows ( $21-30 \mathrm{dph})$ in $1.0 \mathrm{~m} / \mathrm{sec}$ current and encounter with different shapes for rotor blade cross sections.

\begin{tabular}{|c|c|c|c|}
\hline Fathead minnow & \multicolumn{3}{|c|}{ Rotor blade cross section profile } \\
\hline in $1.0 \mathrm{~m} / \mathrm{sec}$ flow velocity & Round & Hydrofoil & Pointed \\
\hline Mean Immediate treatment survival rate at $\mathrm{T}_{0}$ & 98.9 & 97.8 & 98.9 \\
\hline Mean treatment survival rate at $T_{3}$ & 98.9 & 96.7 & 97.8 \\
\hline Mean treatment survival rate at $T_{24}$ & 85.6 & 90.0 & 91.1 \\
\hline Conditional mortality (\%) at $\mathrm{T}_{24}$ & 2.2 & 4.4 & 3.3 \\
\hline Treatment mortality (\%) at $\mathrm{T}_{24}$ & 12.2 & 5.6 & 5.6 \\
\hline Delayed mortality $\quad(\%)$ at $T_{3}$ & 0 & 1.1 & 1.1 \\
\hline Delayed mortality $\quad(\%)$ at $\mathrm{T}_{24}$ & 11.1 & 3.3 & 4.4 \\
\hline
\end{tabular}

$\mathrm{T}=$ treatment, lower case numbers indicate hours post treatment. 


\section{Discussion}

In large rivers the highest concentrations of fish early life stages are most often found in backwater habitats (Holland 1986). Backwater habitats are generally characterized by their water velocities (a low kinetic energy environment). The faster currents of main channel waters in large rivers facilitate downstream dispersal for fish larvae from pelagic broadcast spawners such as freshwater drum or white bass (Holland 1986, Sheaffer and Nickum 1986, Scheidegger and Bain 1995). Because early life stages of fish are delicate and easily damaged, physical contact with solid objects present a potential hazard to the survival of these organisms. Of the fish species whose early life stages occur in pelagic, main channel habitats will overlap with proposed areas for deployment of hydrokinetic technologies. Those species are expected to have an increased potential for physical contact or collision with HK rotors (Schweizer et al. 2011). Although fish can use their lateral line to sense obstacles and then change body orientation to evade contact (Coutant and Whitney 2000), the effectiveness of the sensoryresponse system in early life-stage fish is unknown, and weakly swimming or passively drifting larvae and juveniles in strong river currents may not be able to avoid physical contact with moving parts of HK devices or exposure to damaging shear stresses and pressure changes.

The present study examined in a laboratory setting the survival rates of early life stages of selected freshwater fish upon encounter with different rotor blade profiles and over a range of flow conditions. In field settings, the velocity of a blade edge that approaching fish will experience depends on the current velocity, the ground speed of the organism, the relative position of fish along the rotor blade (e.g., hub vs. tip) and the technical specifications of the different HK device designs (Table 8). The relatively low flow velocities we were able to create in the laboratory flume were nonetheless similar to expected cut-in speed and velocities of blade edges near the rotor hubs and included the lower performance envelope of proposed hydrokinetic technologies (DOE 2009).

Generally, compared to holding and flume passage controls, the presence of the blade profile in the path of the drifting YOY fish increased mortality rates over the 24-hour post-test holding period. Results also suggested that the degree of ontogenetic development of fish, the current velocity, and the shape of the object in the flow path of fish early life stages all influenced mortality rates. However, these possible relationships could not be tested statistically. A quantitative analysis of larval survival across all age groups and flow regimes was not possible because the experiments were constrained by the availability of sufficient sample sizes per treatment group. As noted, natural mortality of the youngest fish larvae was often quite high, resulting in too few fish available to carry out the desired number of replicates. The resulting unbalanced design limited our quantitative analysis to comparisons among treatments and control groups within individual species age groups and flow regimes. The experimental design we used in these exploratory tests did not allow us to determine whether the observed blade 
Table 8. Technical specifications of example hydrokinetic devices and the projected velocities at the leading edges for various positions along the rotor blade. Projected blade velocities are estimated for conditions with optimized river flow and device performance.

\begin{tabular}{|lllll|}
\hline & $\begin{array}{l}\text { Hydro Green } \\
\text { Energy, LLC }\end{array}$ & $\begin{array}{l}\text { Free Flow } \\
\text { Power(FFP) }\end{array}$ & Verdant Power & DOE Reference \\
model 2
\end{tabular}

*Revolutions per minute.

passage was due to leading edge strike, turbulence and shear stresses in the wake of the blade, or both. Therefore, the results discussed here reflect overall mortality caused by passage near the rotor blade, with no differentiation between possible causal mechanisms. The experimental procedure could be modified in future tests by the inclusion of a treatment in which fish are inserted directly into the wake of a blade profile, without the possibility of blade strike. Comparisons among the passage treatment, wake treatment, and the passage control without blade exposure would permit a distinction between potential strike mortality and passage mortality associated with exposure to wake turbulence. Not surprisingly, the largest mortalities among fish early life stages was observed for yolk-sac larvae exposed to passage by the leading edge of representative blade profiles, and the mortality rates decreased with progressing age expressed in days post hatching (dph). The largest juvenile fish that we tested, walleye/sauger hybrids at $30 \mathrm{dph}$ and crappies at $45 \mathrm{dph}$, experienced essentially no treatment 
mortality because they were apparently able to avoid contact with the blade profiles at flow velocities of 0.5 and $0.85 \mathrm{~m} / \mathrm{sec}$ respectively.

We had sufficient numbers of striped bass post-yolk-sac larvae (11-14 dph) to compare the effects of different approach velocities and blade profiles. At an approach velocity of $0.85 \mathrm{~m} / \mathrm{sec}$, fish survival declined over the course of the 24-hour post-test holding period for all 3 blade profiles. At this velocity, the highest mean survival appeared to be associated with a hydrofoil-shaped blade profile and the lowest survival with a pointed blade profile. However, there was little difference among the blade profiles in terms of treatment mortality (corrected for holding control mortality), and the large standard deviations associated with these estimates suggest that the differences were not significant. At the highest approach velocity of $1.15 \mathrm{~m} / \mathrm{sec}$, survival for the cylindrical blade profile was considerably lower than for the hydrofoil-shaped profile. However, because of high mortality in the passage-control groups, the treatment mortalities were not greatly different among different blade shapes. In a comparison of the effects of different approach velocities for a given blade profile, treatment mortality at $\mathrm{T}_{24}$ for striped bass exposed to the cylindrical blade profile was smaller at $0.85 \mathrm{~m} / \mathrm{sec}$ than at $1.15 \mathrm{~m} / \mathrm{sec}$. In contrast, following exposures to the hydrofoil or the pointed blade profile, mortality rates at $\mathrm{T}_{24}$ for striped bass YOY were lower at an approach velocity of $1.15 \mathrm{~m} / \mathrm{sec}$ than at $0.85 \mathrm{~m} / \mathrm{sec}$.

Tests with different ages of striped bass early life stages allowed a consideration of the effects of age/size on strike mortality for this species. Although the unbalanced design with unequal sample sizes or missing treatments for blade shapes or age groups prevented statistical interpretation of the data, the observed mortality rates for striped bass early life stages generally decreased with increasing age (dph). For example, while striped bass at $1 \mathrm{dph}$ exposed to passage by a cylindrical profile in currents of $0.5 \mathrm{~m} / \mathrm{sec}$ experienced up to $67.8 \%$ treatment mortality at $\mathrm{T}_{24}$, at age 11-14 dph the mortality rate at $\mathrm{T}_{24}$ decreased to $28.8 \%$ at a faster current velocity of $0.85 \mathrm{~m} / \mathrm{sec}$. These observations are probably because moredeveloped fish larvae and juveniles exhibit a more rapid and effective escape response (Gibb et al. 2005). The striped bass yolk-sac larvae have little ability to sense and avoid the approaching blade, and are likely to be more sensitive to the forces associated with blade contact and fluid shear and turbulence. On the other hand, the older striped bass post-yolk-sac larvae have greater ability to sense and resist these forces.

The ability of larger fish to sense and resist blade passage was apparent for other fish species that were tested only at later (post-larval) life stages. For example, the walleye/sauger hybrids (age $30 \mathrm{dph}$ ) exhibited no treatment mortality at $\mathrm{T}_{24}$ because they successfully avoided immediate contact with the blade profile by swimming upstream against a $0.5 \mathrm{~m} / \mathrm{sec}$ current. 
Similarly, no mortalities were observed among crappies at age $45 \mathrm{dph}$ immediately after passage by the blade, or at time 3 hours post treatment.

It must be noted that the fish early life stage mortalities observed in this laboratory study were for conditions much simplified from real world applications. The design of this study allowed the observation of survivorship upon exposure to the leading edge of different rotor blade profiles that were stationary and in the direct path of the fish. In a real world setting, in addition to head-on encounter as simulated in this study, the blade of a rotating hydrokinetic turbine would approach fish at angles, resulting in a more complicated exposure that could also result in the organism being pushed aside or abraded.

Furthermore, the severity of contact with a rotating blade is expected to depend also on fish orientation and swimming behavior (Solomon 1988), and position of contact along the edge of the blade as measured by distance from the hub of the rotor (Coutant and Čada 2005). The approach velocities we created in the laboratory flume are representative of the lower radial velocities found nearer to the hub or mid-blade of an HK rotor. Velocities at the outer edges of the blades would be higher and would be expected to cause higher fish mortalities because of direct strike or greater fluid forces (McEwan and Scobie 1992, in Turnpenny 1998).

A noteworthy observation was that mortality rates in holding controls for fish age $11 \mathrm{dph}$ and older remained relatively stable from $T_{0}$ to $T_{3}$ but mortalities were substantially higher at $T_{24}$ (Figure 6 to Figure 11). We also noted that fish apparently receiving some traumatic injury in passage by the leading edge of the blade were usually still alive at $T_{0}$ and $T_{1}$ but typically had expired by $T_{3}$. For future tests with these fish early life stages it would be reasonable to shorten the total time of observation. We suggest that the reporting of mortality rates obtained for $\mathrm{T}_{3}$ may provide sufficient information to draw biologically relevant conclusions from these laboratory studies. The reduction in post-test observation time would greatly increase the number of samples that could be processed within 12 hours. It is also important to consider the eventual population-level effects of blade passage mortality among these fish early life stages, given the typically high natural mortalities in the natural environment (and in our experiments). Fish species whose early life stages are normally found in the surface and middepths of large rivers are usually broadcast spawners that use high fecundity as a reproductive strategy. That is, many eggs and larvae are produced, and many of these will die because of natural causes. The population-level risk of additional fish early life stage mortality from passage near a single HK device is almost certainly negligible. However, the potential cumulative effects of passage through hundreds of turbines in a commercial project, located close together in a river reach, are unknown and will eventually need to be considered. The issue of population-level effects arising from mortality of early life stages has been discussed for many years in association with cooling system entrainment into steam-electric power 
plants. A variety of predictive models have been developed to help put the losses into perspective, e.g., by expressing the early life stages losses in terms of equivalent adults (Dixon et al. 2003) or a reduction of the size of harvested fish stocks (Newbold and lovanna 2007).

In summary, our exploratory studies of the effects of blade strike on freshwater fish early life stages suggest that there are differences in mortality attributable to different blade profiles, different approach velocities, different fish species, and different fish life stages. In order to confirm and expand on these results, future laboratory experiments should use greater sample size numbers and could include:

1. Tests using moving blade profiles with the actual dimensions of an operating HK device. These profiles could include leading edge shapes characteristic of regions of the blade near the hub, mid-blade, and tip (if different).

2. Tests with higher water velocities to better simulate the forces associated with direct strike and shear stresses found at the rotor blade tips.

3. Testing more species at a wider range of sizes. For example, differences in treatment effects were found between striped bass yolk-sac larvae (1 dph) and post-yolk-sac larvae (11-14 dph). Larger fish (postlarvae of other species) appeared to be able to avoid blade strike entirely or, if struck, were not injured by the same forces that caused mortality among very young larvae. It would be useful to perform a series of passage tests with a complete set of larval and post-larval/early juvenile life stages.

4. The nature of fish-blade interaction is a significant uncertainty, and fish strike problems are potentially amenable to mitigation by changes in blade design. Interactions cannot be easily examined in a field setting, but could be analyzed in the laboratory with highspeed video cameras. Although larger juvenile walleye/sauger and crappies could be seen avoiding the blade in these tests, the movements of the smallest, transparent larvae could not be tracked visually. The observed mortalities among the yolk-sac and post-yolk-sac larvae may have resulted from downstream turbulence and shear stresses in the wake of the blade as well as from direct physical contact with the blade leading edges. Greater effort to employ a high-speed video camera in conjunction with finescale ADV water velocity measurements might help better describe the fish-blade interactions, and how those interactions vary with fish species and size. 


\section{References}

Čada, G. F., C. C. Coutant, and R. R. Whitney. 1997. Development of Biological Criteria for the Design of Advanced Hydropower Turbines. Prepared for the U.S. Department of Energy, DOE/ID-10578.

Čada, G., M. Bevelhimer, K. Riemer, and J. Turner. 2010. Effects on Freshwater Organisms of Magnetic Fields Associated with Instream Hydrokinetic Turbines. FY 2010 Annual Progress Report. Prepared for the Wind and Water Power Technologies Program, Office of Energy Efficiency and Renewable Energy, U.S. Department of Energy, Washington, DC.

Cohen, J. (1988) "Statistical Power Analysis for the Behavioral Sciences (2nd Edition)," Lawrence Earlbaum Associates, Hillsdale, NJ.

Coutant, C. C., and R. R. Whitney. 2000. Fish behavior in relation to passage through hydropower turbines: a review. Transactions of the American Fisheries Society 129:351-380.

Coutant, C. C. and G. F. Čada. 2005. What's the future of instream hydro? Hydro Review $\operatorname{XXIV}(6): 42-49$.

Dixon, D. A., J. A. Veil, and J. Wisniewski (eds.). 2003. Defining and Assessing Adverse Environmental Impact from Power Plant Impingement and Entrainment of Aquatic Organisms. A.A. Balkema Publishers, Lisse, The Netherlands. 291 p.

DOE (U.S. Department of Energy). 2009. Report to Congress on the Potential Environmental Effects of Marine and Hydrokinetic Energy Technologies. December 2009. 89 p. + appendices. http://www1.eere.energy.gov/windandhydro/marine hydro market acceleration.html.

EPRI (Electric Power Research Institute). 2011. Evaluation of Fish Injury and Mortality Associated with Hydrokinetic Turbines. Palo Alto, CA. Report \# 1024569. November 2011.

FERC (Federal Energy Regulatory Commission). 2012. Federal Energy Regulatory Commission, Hydrokinetic Projects. Available online: http://www.ferc.gov/industries/hydropower/indusact/hydrokinetics.asp. (Accessed March 2012).

Gibb, A. C., B. O. Swanson, H. M. Wesp, C. Landels, and C. Liu. 2006. Development of the escape response in teleost fishes: Do ontogenetic changes enable improved performance? Phys. Biochem. Zool. 79:7-19.

Holland, L. E. 1986. Distribution of early life history stages of fishes in selected pools of the Upper Mississippi River. Hydrobiologia 136: 121-130.

McEvan, D. and G. Scobie. 1992. Estimation of the hydraulic conditions relating to fish passage through turbines. Contractors Report to National Power Aquatic Technology Group, Fawley, 
Reference NPCOOI. National Engineering Laboratory, East Kilbride, Glasgow, G75 OQU, UK., in (Turnpenny 1998).

Newbold, S. C. and R. Iovanna. 2007. Population level impacts of cooling water withdrawals on harvested fish stocks. Environmental Science and Technology 41(7):2108-2144.

Normandeau Associates, Inc. 2009. An Estimation of Survival and Injury of Fish Passed Through the Hydro Green Energy Hydrokinetic System, and a Characterization of Fish Entrainment Potential at the Mississippi River Lock and Dam No. 2 Hydroelectric Project (FERC No. P-4306) Hastings, Minnesota. Final Report. December 2009. Available online:

http://www.normandeau.com/.

Scheidegger, K. J. and M. B. Bain. 1995. Larval fish distribution and microhabitat use in freeflowing and regulated rivers. Copeia 1:125-135.

Schweizer, P. E., G. F. Čada, and M. S. Bevelhimer. 2011. Estimation of the risks of collision or strike to freshwater aquatic organisms resulting from operation of instream hydrokinetic turbines. ORNL/TM-2011/133. Oak Ridge National Laboratory, Oak Ridge, TN. 40 p. + appendix.

Seitz, A. C., K. Moerlein, M. D. Evans and A. E. Rosenberger. 2011. Ecology of fishes in a highlatitude, turbid river with implications for the impacts of hydrokinetic devices. Reviews in Fish Biology and Fisheries, 21, 481-496.

Sheaffer, W. A. and J. G. Nickum. 1986. Backwater areas as nursery habitat for fishes in Pool 13 of the Upper Mississippi River. Hydrobiologia 136:131-140.

Solomon, D. J. 1988. Fish passage through tidal energy barrages. Dept. Energy Contractor's Report No. ETSU-TID 4056, in Turnpenny (1998).

SonTek ADV ${ }^{\mathrm{TM}}$. 1999. SonTek $10 \mathrm{MHz}$ ADV Acoustic Doppler Velocimeter microprobe. SonTek, Inc., San Diego, CA.

Streameter 2000. Water flow meter Streameter 2000, http://www.OPPO.It, Hydrologic Technologies, Italy.

Sturm, T. W. 2010. Open channel hydraulics, Second Edition. McGraw-Hill, New York. 546 p.

Turnpenny, A. W. H., M. H. Davis, J. M. Fleming, and J. K. Davies. 1992. Experimental studies relating to the passage of fish and shrimps through tidal power turbines. Marine and Freshwater Biology Unit, National Power, Fawley, Southhampton, Hampshire, England. 
Turnpenny, A. W. H. 1998. Mechanisms of fish damage in low-head turbines; an experimental appraisal, in Fish migration and fish bypasses, pages 300-314.

Turnpenny, A. W. H., S. Clough, K. P. Hanson, R. Ramsay, and D. McEwan. 2000. Risk assessment for fish passage through small, low-head turbines. White paper on project no. $\mathrm{H} / 06 / 00054 / 00 / 00$. 